\title{
Political Cosmopolitanism:
}

A Humanized and Socialized Account of Global

Citizenship in Action

by

Shoshana Arielle Stirling

A thesis submitted to the Faculty of Graduate and Postdoctoral Affairs in partial fulfillment of the requirements for the degree of

Master of Arts

in

Philosophy

Carleton University

Ottawa, Ontario

(C) 2017, Shoshana Arielle Stirling 


\begin{abstract}
In this thesis, I propose a humanized and socialized account of cosmopolitan global citizenship. Cosmopolitanism has merits and applicability in our globalized society, but its basis on universalism and impartiality can unjustly homogenize public discourse and limit citizenship activity. In my first chapter I interrogate these concepts and appeal to the capabilities approach to humanize impartiality, making cosmopolitanism more inclusive and diverse. In my second chapter I use Iris Marion Young's social connection model to highlight cross-border relationality and obligations as a basis for the praxis of cosmopolitan global citizenship. In my third chapter I apply the social connection model to bolster the concept of global citizenship as it is used in international service learning projects. Overall this thesis presents an argument for and a guide to working out the activities and obligations of cosmopolitan global citizenship, with the end of addressing injustice on a global scale.
\end{abstract}




\section{Acknowledgments}

The completion of this thesis would have been a significantly more difficult process without the help of the following wonderful individuals, to whom I owe so much.

First, I thank my supervisor, Jay Drydyk. Working with him over the past two years has been a privilege and I have learned so much in the process. Jay has a way of distilling my work and reflecting it back to me so that I can see every nuance. I feel that I have developed so much as a philosopher under his instruction, and this thesis could not have come together without his guidance and insight. I am glad for his support and hope I have done him proud.

I am deeply grateful to Christine Koggel, who has been a constant source of guidance and encouragement for me and for the entire cohort. She works tirelessly to ensure that we have every opportunity to succeed and that we are prepared, both academically and personally, to meet our challenges head-on. I have felt so taken care of at Carleton thanks in no small part to her passion and hard work.

To Sandra Kirkpatrick, the fountain of all knowledge, I owe many thanks. I doubt that Sandy has ever met a problem she couldn't solve, and chatting with her always brightens my day. Thanks also to Kris Waddell, whose patience with my constant refrain of "I have a question..." is not taken for granted. Timmy Grainger was kind enough to read and edit parts of this thesis, and having his input and support during a tense period of time put my mind at ease immeasurably. Additionally, the brainstorming, sympathetic listening, and friendship of Jo Chalupiak, Holly Longair, and Amy Keating over the past 
months has been invaluable and treasured. Graduate school has been a richer and more fulfilling experience with their companionship, and for that I am grateful.

Lastly, I want to thank my family. It has been a particularly turbulent two years for all four of us and we are now emerging on the other side, poised for new beginnings. I am so proud of my brother who is starting nursing school in the fall, and of my parents who are about to start a new chapter of their life together in Chicago. Our unwavering support for each other has made me feel safe in whatever path I pursue, and the love we all share is so much a part of who I am today. This thesis is for them. 


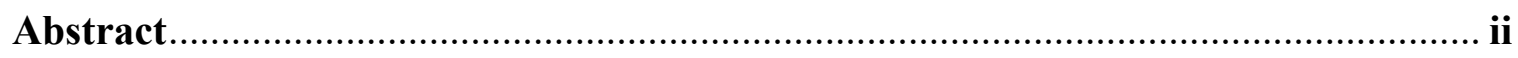

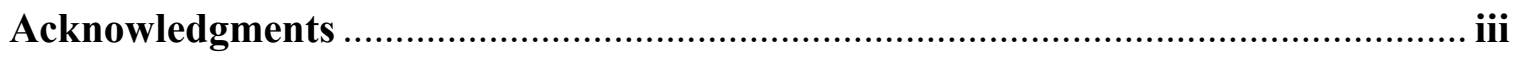

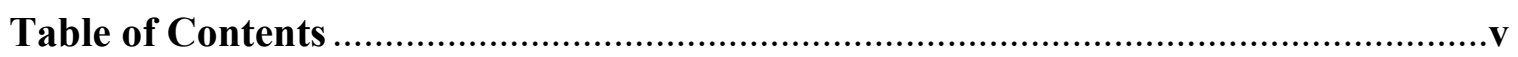

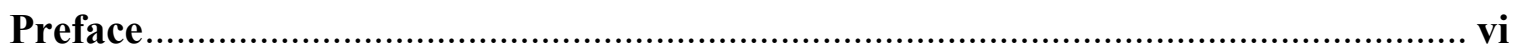

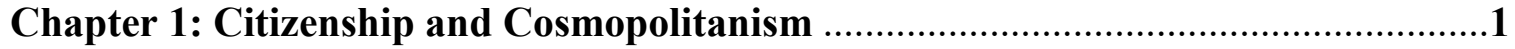

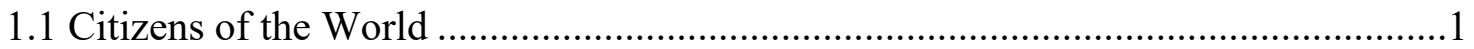

1.2 Citizenship, Liberal Impartiality, and Oppression ..............................................13

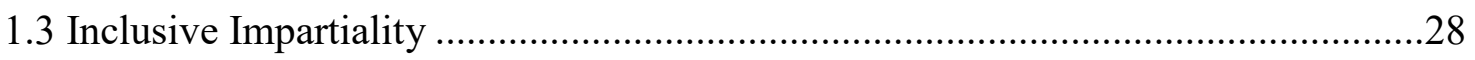

Chapter 2: The Social Connection Model...............................................................40

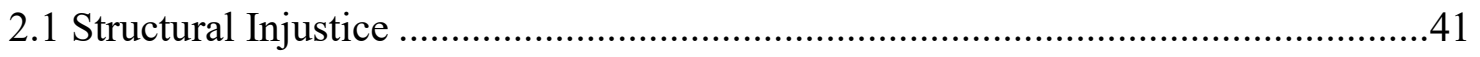

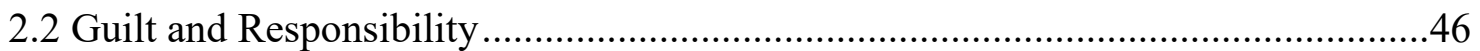

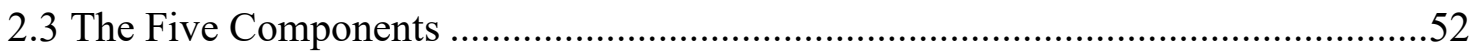

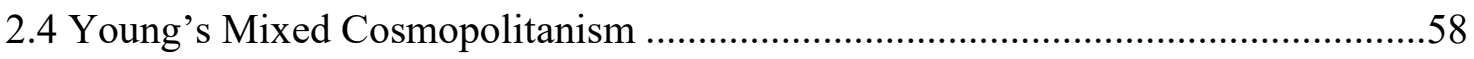

Chapter 3: Cosmopolitan Global Citizenship and International Service Learning ..69

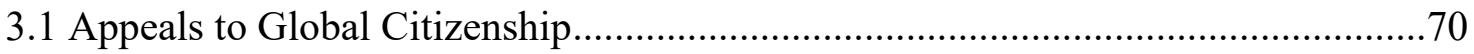

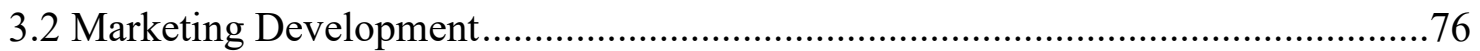

3.3 Applying the Social Connection Model ............................................................91

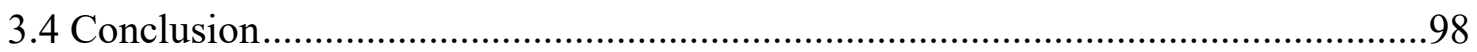

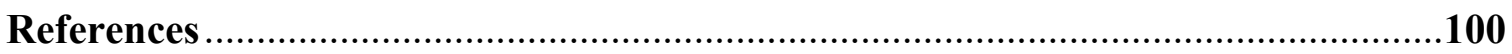




\section{Preface}

In recent years, international experiential learning and international service learning projects have grown in popularity, both through a variety of non-governmental organizations that offer volunteer trips and through increased post-secondary emphasis on travel abroad as a key educative experience. My own interest in international experiential learning and in global citizenship comes from my participation in an Alternative Spring Break volunteer trip to Peru, from which I returned disillusioned and deeply conflicted about the impact these projects are supposed to have. I felt that despite the trip having been presented to me as assistive for the community and for our own personal learning as participants, neither goal was achieved. Our presence at the build site of a new school was more of a hindrance than anything else. The lone local worker, who was the father of one of the schoolchildren, accomplished more on his own than three of us participants accomplished working together - and in half the time. I could not help but wonder, what would have happened if our trip fees had gone not toward funding our stay in Urubamba and our minimal contributions to construction, but to employing skilled locals to do the work better than we could and in half the time? What would have happened had the money that was spent on trinket gifts for the children been redirected to buying bricks for their new school, which were in short supply and difficult to transport? Given these concerns and others, I felt that the benefit some participants felt they had gotten from the trip was greatly outweighed by the good that could have been done had we just stayed home. Yet for some reason we, as participants, collectively felt entitled to be there, to help out, and to be thanked for our efforts. 
Part of the reason I was so disillusioned in the wake of my two-week experience abroad was because the Alternative Spring Break program had been marketed to me as a way to "be the change"-a line so ubiquitous in the world of volunteer trips that I was suspicious of it to begin with. The Alternative Spring Break program overview states that as a service learning initiative, dual emphasis on service to others and learning for one's own personal and academic trajectory is meant to teach participants what it means and what it feels like to be an engaged citizen. Indeed, the strategic plan of the post-secondary institution under whose purview the trip was run promises that "Our graduates will be global citizens whose education and leadership will serve the public good" (Western University 2014, 5). Yet any pre-departure discussions we may have had about global citizenship have not made a lasting impression on me, and the trip experience and the outcomes I perceived are not in line with what I understand global citizenship to be from my own project of sustained research contained herein.

And so, we arrive at the crux of my project: evidence shows that while international service learning projects frequently refer to global citizenship as both a motivation and an outcome of the experience, the trips often do not operate in accordance with those values. This disconnect between theory and practice is not only an unrealized opportunity for practicing global citizenship via international service learning projects. It is a harm that manifests both in the (falsely) elevated self-concept and particular worldview that participants come away with and in the development outcomes of these programs. My project examines in depth what it means to be a global citizen. I will elaborate what a praxis of global citizenship looks like, and apply it to international service learning projects in order to demonstrate both the harm being done by these 
projects and the system of civic education that we are bypassing in the misunderstanding and misapplication of global citizenship theory. In particular, I emphasize that international service learning projects should not be treated just as tools to increase the marketability of graduates. Applying true, cosmopolitan global citizenship to international service learning projects can create educative programs that train global citizens. The global citizen's main goal will not be employability, but rather an enduring commitment to social justice and addressing systemic inequality on a local, national, and global scale.

I undertake this argument in three chapters:

1) Citizenship and Cosmopolitanism

2) The Social Connection Model

3) Cosmopolitan Global Citizenship and International Service Learning

In the first chapter, I discuss cosmopolitanism and its contributions to a concept of global citizenship. I interrogate the theoretical foundations of cosmopolitanism and of citizenship, arguing that cosmopolitanism imparts an important and fundamental justice focus to the project of global citizenship while at the same time involving homogenizing norms of liberal impartiality. I appeal to the capabilities approach to humanize impartiality, making it inclusive and recognizant of the vast diversity of human needs. Inclusive impartiality based on the capabilities approach contributes to a stronger understanding of cosmopolitanism upon which to build a concept of global citizenship.

In the second chapter, I use Iris Marion Young's social connection model to ground cosmopolitan global citizenship in global relationality and obligations. In 
particular, I argue for an interpretation of the social connection model wherein it serves as a framework for cosmopolitan global citizens to examine their particular relational position and obligations. The five components of the social connection model—nonisolation, judging background conditions, a forward-looking focus, emphasis on shared responsibility, and the prescription that this responsibility can only be discharged through collective action —encourage individuals to take responsibility for their role in structural injustice in an active and ongoing praxis of cosmopolitan global citizenship.

In my third and final chapter, I examine the applications of the social connection model to a phenomenon often associated with the pursuit and practice of global citizenship: international service learning projects. Referring to the work of Rebecca Tiessen and Robert Huish, and drawing on trip descriptions and testimonial evidence, I show that international service learning projects often appeal to the concept of global citizenship but seem to lack solid theoretical grounding. This results in an ineffective civic education for trip participants, and in a kind of cognitive dissonance that impairs their ability to engage productively with the project of global justice. I show how using the social connection model as a tool for reflection can help shape ISLP participants' feelings and experiences into an ongoing commitment to global justice, realized through the praxis of cosmopolitan global citizenship. 


\section{Chapter 1: Citizenship and Cosmopolitanism}

In this chapter, I explore the concept and function of global citizenship. I argue that a viable concept of global citizenship must be humanized and socialized ${ }^{1}$ in order to be sensitive to differences in power, resources, and capacity. Paying attention to these issues will ensure that the oppression perpetuated by liberal impartiality — which is endemic to many understandings of citizenship, and which demands exclusion of situational and personal particularities - is not replicated on a global scale. I begin by examining prominent accounts of global citizenship, including appeals to cosmopolitanism and to the notion of citizenship as a praxis. I then move on to explore the ways in which the building blocks of these contributions can involve oppressive norms associated with liberal impartiality. To support this critique, I offer a brief historical overview demonstrating the ways in which modern nation-state citizenship is oppressive and flawed. Finally, I commence my positive project of humanization and socialization by grounding cosmopolitan global citizenship in the capabilities approach. A capabilities focus will humanize impartiality and make it inclusive of all manners of striving for a good life.

\subsection{Citizens of the World}

There is no single accepted notion of what it means to be a global citizen. However, there are several definitions that may provide us with a helpful starting point for assessing how

\footnotetext{
${ }^{1}$ By "humanized" global citizenship, I mean that global citizenship must take into account the most salient aspects of persons in a way that acknowledges diversity, rather than homogenizing differences. By "socialized" global citizenship, I mean that global citizenship must be sufficiently aware of local and global relationality, and pay specific attention to the ways in which these relationships can promote marginalization and disadvantage.
} 
global citizens orient themselves toward the world. For example, Joanne Rennick and Michael Desjardins cite the Oxfam definition of global citizenship:

Global Citizenship is about understanding the need to tackle injustice and inequality, and having the desire and ability to work actively to do so. It is about valuing the Earth as precious and unique, and safeguarding the future for those coming after us. Global Citizenship is a way of thinking and behaving. It is an outlook on life, a belief that we can make a difference. (Rennick and Desjardins 2013, 7)

Given this definition, it seems that Oxfam's model global citizen would be concerned with effective systemic solutions to injustice, would consider herself to be a steward of our planet and its resources, and would not merely think about these issues but translate her priorities into real-world actions. Notably, Oxfam does not specify whether these actions should take place at a local, national, or global level. This omission is perhaps strategic in that it leaves global citizenship open to a variety of agents with differing reaches or spheres of action - that is, global citizenship is, or should be, cross-cultural and non-exclusive because there are many ways for one to engage in global citizenship. For instance, someone living an affluent life in the Global North likely has more power, privilege, and resources available to extend their impact beyond their immediate community. The freedom to travel is an example of one of the tools that a global citizen may (mis)use but that remains unavailable to a large swath of the world's populationwhether for financial, political, or personal reasons. But that does not exclude people who cannot travel from being global citizens. Oxfam's ultimate interpretation of global citizenship as "a way of thinking and behaving" implies that being a global citizen relies not on resources and networks, but rather on an attitudinal disposition that leads to concerted action in a variety of forms. 
The cross-cultural relevance and accessibility of global citizenship to all segments of society regardless of location, financial resources, and other considerations is endorsed by Nigel Dower when he explains that while all people are in principle global citizens, global citizenship encompasses "a wide spectrum of cases from a fully fledged form of self-conscious engagement and active responsibility... through to cases where the category applies hypothetically, in order to cover cases where people have no wider 'causal footprints' beyond the local and thus have no need for active engagement at other levels" (Dower 2002, 38). The potential for global citizenship regardless of the range of "causal footprints" thus leads us into an examination of what global citizenship consists in beyond one's mental orientation toward their role in the world. James Tully's account of global citizenship is helpful here in that he emphasizes the doing component as allimportant; he reconceptualizes citizenship as a praxis, rather than as a legal status. Tully accomplishes this by introducing the idea of diverse citizenship as a "multiplicity of different practices of citizenship in the West and non-West... a situated or 'local' practice that takes countless forms" (Tully 2014, 8). Diverse citizenship is thus described not in terms of the government but rather in terms of the activities of the governed. Tully elaborates, "When citizenship is defined in relation to the rule of law, then it is seen as an 'opportunity' concept: a status a person or group has in virtue of being recognized as the subject of a normative order and the bearer of rights and duties. When it is defined in relation to democracy, then it is seen as an 'exercise' concept: a practice or activity that citizens engage in within or over a normative order" (Tully 2005).

A diverse idea of citizenship means that the citizen is only a citizen insofar as she undertakes a particular set of activities and attitudes. That is, diverse citizenship as a set 
of "negotiated practices as praxis" in particular contexts—or "what citizens do and the ways they do them" (Tully 2014,35) - rejects the primacy of institutions and highlights people and their activities as the primary consideration. On this reading, one does not hold citizenship so much as one does citizenship. Tully affirms this in his statement "Citizenship is not a status given by the institutions of the modern constitutional state and international law, but negotiated practices in which one becomes a citizen through participation” (Tully 2014, 9). Tully's emphasis on global citizenship consisting in negotiated practices is highly compatible with Oxfam's emphasis on global citizenship as a way of thinking and behaving; in each case, concerted action predicated on principled global concerns is the full realization of one's global citizenship. Additionally, Dower's approach to global citizenship supports Tully's citizenship-as-praxis in that both accounts emphasize that global citizenship comes not from institutions but from citizens themselves. In Dower's case, he argues that institutions are crucial to the maintenance and mediation of global citizenship but that "we need what H.G. Wells called a 'mental cosmopolis' (through which we 'intend world community' in John Macmurray's phrase before the intention is fully actualised (Macmurray 1957))" (Dower 2002, 32). Though Tully would likely put less stock in institutions than Dower seems to, perhaps diverse citizenship — and the proclivity for its constitutive civic activity—can be seen as a praxis of "intending world community" in the way that Dower envisions.

Tully's diverse citizenship is therefore "global" in two ways. First, since it is a praxis that rests with the citizen herself rather than a status that rests on an external system, diverse citizenship is "global" in that it is something that every person can practice and attain from within a variety of contexts. Diverse citizenship is "not brought 
into the world by coercion, the institutions of law, the nation state or international law, but by citizens engaging in civic activities and creating civic worlds" (Tully 2014, 38). The multiplicity of actors and contexts that go into creating these civic worlds means that virtually anybody anywhere is "eligible" for participation in this kind of citizenship - it is global in accessibility. Second, diverse citizenship is "global" in that it is deeply relational. Tully highlights that civic citizenship always exists in relationships, including "relationships among roughly equal citizens exercising power together in citizen-citizen relationships of solidarity, civic friendship and mutual aid" (Tully 2014, 41). These citizen relationships of solidarity, friendship, and aid link us together both within and across borders, providing an inclusive and collaborative relational landscape or "civic world" from which to address issues of global import and impact. The intended world community that Dower mentions is manifest in the practitioners, relationships, and subject matter of diverse citizenship.

The notion of world community is not new, and has undergone many incarnations in the form of cosmopolitanism. Cosmopolitanism, according to some, can be seen as the core of the "global" in global citizenship. However, cosmopolitanism and global citizenship are not synonymous; global citizenship need not revolve around universal morality in the way that cosmopolitanism does. That said, cosmopolitanism is valuable to global citizenship because it provides a key motivation to actually live a global ethic rather than merely acknowledging one. Dower argues that "Understanding one's responsibilities as a member of a global moral community would... help convert acceptance of the principle [of a global ethic] into concerted action" (Dower 2002, 34). As I will illustrate in chapter 2 (pg. 51), action is absolutely essential to global citizenship 
because global citizenship is not just an orientation or belief, but a practice. The sense of belonging and community is an important factor in the realization of this program of action, and I take this to be a key contribution of cosmopolitanism to the concept of global citizenship. It serves both as the moral justification and as the political impetus for a practice of global citizenship.

The cosmopolitan emphasis on community is traceable to the Stoics, whose aim it was to "replace the primacy of the individual's relation to the polis with the idea of the cosmos as encompassing the whole of humanity in an ideal of universal belonging" (Held 2010,15). That is, the Stoics sought to expand one's sense of belonging and unity beyond the finite political community to the entirety of natural existence. Though the Stoic sense of cosmopolitanism is more of a spiritual or religious project in some ways than a political one, the expansion of belonging is important for us to consider for its citizenship implications. If one's notion of belonging is restricted to the polis- the conventional political unit of the city-state or nation-state — one's sphere of concern and action will likely be limited to their immediate surroundings, and their citizenship will correspondingly be carried out on a micro-scale according to the rights and obligations enumerated by the polis. Conversely, if one sees oneself as having a place of belonging not just in a political-geographic order but in the entirety of creation itself, one's citizenship will likely be informed by a belief in natural rights inherent to all—or at least, a belief in equal consideration for all —and responsibilities not just to one's arbitrary political-geographic membership but to a much wider relational community. It is this kind of macro-citizenship and broadened sense of belonging and obligation we see reflected in Oxfam's focus on stewardship of the planet Earth, in Tully's eschewing of 
the government in favour of focusing on the activities of the governed wherever and however they may be ${ }^{2}$, and in Dower's reference to the "mental cosmopolis" of intended world community. These notions of global citizenship deal with the citizen abstracted from her institutional context, situating her instead relative to other citizens, to the world, and to their collective place in it.

In addition to the Stoic notion, David Held cites two more prominent understandings of cosmopolitanism. Kantian cosmopolitanism relates to public reason, revolving around the assertion that "An individual's entitlement to enter the realm of public reason is mirrored in the right to free membership in the global community of argument" (Held 2010, 15). This entitlement is referred to as "cosmopolitan right." Understood as the right to enter and be heard within and across political communities without constraint, cosmopolitan right "transcends the particular claims of nations and states and extends to all in the 'universal community.' It connotes a right and duty which must be accepted if people are to learn to tolerate one another's company and to exist peacefully. It is the condition of cooperative relations and of just conduct" (Held 2010, 43). Cooperative relations for the end of justice and global harmony are part of the systemic focus of cosmopolitan global citizenship, and positioning the cosmopolitan right as a transcendental duty makes the project of cosmopolitanism an inherently universal and collaborative one. In particular, the transcendental nature of cosmopolitan right echoes the cross-cultural and non-exclusive notion of global citizenship expressed in Oxfam's definition and in the phenomenon of intended world community. It is important

\footnotetext{
${ }^{2}$ While I read a cosmopolitan ethos into Tully's account of global citizenship, I must mention that Tully seems explicitly hostile to cosmopolitanism in certain incarnations. In particular, he opposes "selfdescribed universalism and cosmopolitanism as... circular parochialism and fear of alterity" (Tully 2014, 34). The cosmopolitanism of which this is a valid critique is not the cosmopolitanism I support or argue for here, as I will make clear in my forthcoming challenge of liberal impartiality and homogenization.
} 
for Kantian cosmopolitanism that all people, regardless of political or demographic affiliation, be able to take their rightful place in the universal community —and it is this taking of place, this entering and being heard within and across political communities, that begins the practice of global citizenship. Indeed, it is with Kant that the term weltbürger (world citizen) originated, showing a solid historical and theoretical connection between cosmopolitanism and global citizenship.

The third notion of cosmopolitanism that Held defends is a more recent one with three mandates. The first, egalitarian individualism, "simply states that individuals are the ‘ultimate units of moral concern"” (Held 2010, 15). The second, reciprocal recognition, "implies that the equal moral worth of persons should be recognized by all" (Held 2010, 15). The third and final mandate, impartialist reasoning, maintains "that each person's claims are to enjoy impartial consideration in public deliberation and argument" (Held 2010, 15). It is important to note here that the three understandings of cosmopolitanism that Held presents - the Stoic, the Kantian, and the modern — are not at odds with one another. Rather, they demonstrate the evolution of cosmopolitanism in accordance with increasing globalization and its accompanying political projects. The Stoic notion of world citizenship and universal belonging underpins the Kantian cosmopolitan right, for without a concept of universal belonging it would be nonsensical to assert one's entitlement to public reason on a universal scale that transcends finite politicalgeographic units. Similarly, the tripartite contemporary understanding of cosmopolitanism does not cancel out the Kantian (and by extension, the Stoic) understanding of cosmopolitanism. Rather, the principles of egalitarian individualism, reciprocal recognition, and impartialist reasoning can be interpreted as a proposed set of 
norms for the Kantian universal community of public reason that is being built by the ongoing globalization process. The three understandings of cosmopolitanism that Held presents are thus highly compatible with one another, which Held recognizes in the specific model of cosmopolitanism he defends.

Drawing on each of the three understandings, Held sets out the project of cosmopolitanism as "to disclose the ethical, cultural, and legal basis of political order in a world where political communities and states matter, but not only and exclusively" (Held 2010, 67). Held's model of cosmopolitanism "recognizes each person as an autonomous moral agent entitled to equal dignity and consideration" (Held 2010, 15). This is reflective of all three components of the modern understanding of cosmopolitanism. Moreover, and importantly for understanding global citizenship as a praxis, Held's model "promotes a way of translating individual agency into collective political enterprises" (Held 2010, 15). To this end, Held's cosmopolitanism relies on eight paramount principles he contends can be universally shared, and that form the basis for fostering and protecting each individual's equal significance in what he calls "the moral realm of humanity", which I take to be tantamount to Kant's "universal community" and Dower's "global moral community". These principles are (i) equal worth and dignity; (ii) active agency; (iii) personal responsibility and accountability; (iv) consent; (v) collective decision-making about public matters through voting procedures; (vi) inclusiveness and subsidiarity; (vii) avoidance of serious harm; and (viii) sustainability (Held 2010, 69).

Held provides two metaprinciples to justify his list of eight cosmopolitan principles: the metaprinciple of autonomy (MPA) and the metaprinciple of impartial reasoning (MPIR). He describes the MPA as a notion embedded in the culture of 
democracy and emerging democracies, in that it is "a commitment or pre-commitment to the idea that all persons should be equally free" (Held 2010, 84). Held maintains the MPA's cross-cultural validity against objections that its adoption/enforcement is an acquiescence to Western political discourse, arguing that endorsement of the MPA is not cultural/political hegemony but rather a recognition that certain languages seek to nurture the notion of equal status and worth while others seek to suppress it. The MPIR, which Held argues is similarly universal in its application, is a "social open-ended, moral perspective... a way for focusing our thoughts and testing the intersubjective validity of our conceptions of the good" (Held 2010, 85-86). Held's principles and metaprinciples of cosmopolitanism constitute a thorough theoretical grounding for the practice of global citizenship that is universal, but flexible and ethically neutral. He clarifies that his eight principles are not specified once and for all, but rather "while cosmopolitanism affirms principles which are universal in their scope, it recognizes, in addition, that the precise meaning of these is always fleshed out in situated discussions... there is an inescapable hermeneutic complexity in moral and political affairs which will affect how the eight principles are actually interpreted" (Held 2010, 80). It is this diversity of interpretations and applications that lead Held to classify his notion of cosmopolitanism as neither "thick" nor "thin," but instead as "layered."

Cosmopolitanism is perhaps the first iteration of an idea of global citizenship. So, what does it contribute to contemporary understandings of global citizenship, and why should we continue to refer to its principles? One problem with global citizenship, as John D. Cameron asserts, is that "Not all understandings of global citizenship contribute to global justice" (Cameron 2013, 25). Cosmopolitanism, however, is fundamentally 
concerned with issues of justice through its focus on "the moral obligations which all human beings hold towards one another-regardless of where they may happen to live" (Cameron 2013,23). The principles of cosmopolitanism contribute to the project of global justice by asserting the equality and agency of all people, and by highlighting our personal responsibility and accountability when things go wrong in this regard. Injustice taking place on the other side of the world is not so remote for a global citizen who sees herself as a member of a larger moral community; her sphere of concern is broadened so that she understands that injustice to have relevance to her life, or vice versa. This understanding, contextualization, and integration of global issues with one's personal motivations leads to the kind of civic activity that makes intended world community a reality - citizen relationships built on the values and practice of solidarity, friendship, and mutual aid. And, crucially, "Cosmopolitan principles and actions are urgently needed now because of the multiple human and ecological crises generated by contemporary globalization and the growing mutual interconnectedness that globalization brings about" (Cameron 2013, 26-27).

However, while cosmopolitanism contributes a valued and needed justice focus to global citizenship, cosmopolitanism's impartiality may be troubling if it relies on prevailing liberal conceptions of impartiality. Liberal impartiality is often used to set standards about what issues are inappropriate to include in civic society and public discourse, based on whether the issues are too individual, too situated, or not relevant to the public interest. Iris Marion Young elaborates, "The stances of detachment and dispassion that supposedly produce impartiality are attained only by abstracting from the particularities of situation, feeling, affiliation, and point of view" (Young 1990, 97). 
While this may seem a valuable goal, Young argues that liberal impartiality as a central feature of civic society creates a false dichotomy between reason and feeling, where feeling and the body are rejected and reason allegedly provides "a point of view outside concrete situations of action, a transcendental 'view from nowhere' that carries the perspective, attributes, character, and interests of no particular subject or set of subjects" (Young 1990, 100). This is objectionable because the impact of privileging reason over feeling is that "The traditional public realm of universal citizenship has operated to exclude persons associated with the body and feeling - especially women, Blacks, American Indians, and Jews" (Young 1990, 97). In my view, this exclusion creates institutions in which the citizenship of some counts for more than the citizenship of others.

Claims about social justice often have to do with the "most particular aspects of persons", as Young calls them, yet these are the aspects that liberal impartiality asks us to set aside. For example, the fact that I am a queer Jewish woman may have enormous bearing on the way in which I am able to move through the world, yet liberal impartiality demands that I ignore those aspects of myself when making arguments in and about public life. These aspects of myself may tell me the most about how our social and political spaces function and how they should change, so to require that I set them aside in order to make arguments about our social and political spaces is incoherent and can lead to oppressive outcomes. People are often oppressed based on the particular aspects of themselves, so bringing these particular aspects into the public sphere should not only be permitted but encouraged if we are to remedy situations of oppression. Liberal impartiality prevents or discourages this by regulating democratic processes and public 
discourse so that citizens are only permitted to bring a select set of concerns to the table - the concerns that are "universal" and applicable to everyone. If one happens to have needs and interests that are not the needs and interests of most other people, those needs and interests are not welcome in public discourse governed by liberal impartiality.

If cosmopolitanism is important to global citizenship, and liberal impartiality is important to cosmopolitanism, then we must interrogate whether this is really a global citizenship that can be accepted and practiced by everyone. I am not prepared to abandon cosmopolitanism altogether, due to its valuable contribution of a focus on justice and its compatibility with a praxis-based notion of global citizenship. Rather, it is simply the reliance on liberal impartiality that makes cosmopolitanism a non-global global ethic. In the next section, I present an account of the ways in which liberal impartiality has functioned as an oppressive force within modern, non-global understandings of citizenship. My discussion is meant to caution that we should take care not to replicate these oppressive outcomes the world over in cosmopolitan global citizenship. I will also argue that rejection of impartiality does not necessitate rejection of cosmopolitanism. Rather, I argue for a way to modify impartiality to make it (and consequently, cosmopolitanism) more inclusive.

\subsection{Citizenship, Liberal Impartiality, and Oppression}

Citizenship: membership, determined by formal factors such as place of birth, parentage or act of naturalisation, of a political community (generally a nationstate) by virtue of which one has legally defined rights (including political rights not necessarily accorded to other residents) and duties, and moral responsibilities to participate in the public life of one's political community. In so far as the idea of global citizenship builds on the back of citizenship itself, the question is: what element or elements above are the important ones? (Dower and Williams 2002, xix) 
The definition above, offered by Nigel Dower and John Williams in the glossary of their book Global Citizenship: A Critical Introduction, expresses how most of us likely already conceive of citizenship: as something that is given to us by the nation-state, through which we are guaranteed certain things and through which we are obligated to others. For example, in a democratic nation-state with representative government, citizens are usually guaranteed the right to vote and — some would argue—-have the corresponding responsibility to exercise that right when elections are held. Dower and Williams close their definition by challenging us to consider which of the elements mentioned as components of citizenship are salient in constructing an understanding of global citizenship. So, in partial response to the question posed by Dower and Williams and based on my critique of cosmopolitanism above, I submit that we must search for understandings of global citizenship that do not rely on liberal impartiality to structure public discourse either within nation-states or across the globe. Moreover, our current understandings of citizenship and cosmopolitanism can disempower and oppress, indicating that we cannot simply modify citizenship with cosmopolitanism and call it "global citizenship", lest the oppression carried out by nation-state citizenship and liberal impartiality be replicated on a global level. In what follows, I intend to point out the oppressive structures in citizenship not to delegitimize citizenship as a concept, but to challenge a particular concept of citizenship and the institutional trappings that accompany it. This section contains a disassembly of the concepts of citizenship and liberal impartiality, setting the stage for their reassembly into a fortified concept of cosmopolitan global citizenship. 
James Tully's description of the status quo of nation-state citizenship, which he calls "modern citizenship", is roughly equivalent to the way Dower and Williams understand citizenship above. Tully, however, intimates context and historical insight that urge us to interrogate this understanding of citizenship and the nation-state system on which it relies. Tully says that our modern citizenship is "the modular form of citizenship associated with the historical processes of modernization and colonization: that is, (1) the modernization of the West into modern nation states with representative governments... and, in tandem, (2) the dependent modernization and citizenization of the non-West through colonization" (Tully 2014, 8). I want to critically assess two separate but related background components of citizenship that emerge from Tully's definition: modern nation states, and colonization. In my discussion of these components, I will offer reasons to look askance at conceptions of citizenship that depend on the nation-state and its institutions, rather than on democracy and its associated activities.

The nation-state, referenced by Tully and by Dower and Williams, is the locus of modern citizenship. Citizenship in this case indicates a sort of exclusive relationship between a person and a nation-state, marking the citizen as officially subject to the norms and operations of the nation-state and marking the nation-state as the citizen's proper domain of concern and activity. The exclusivity of the modern nation-state can be traced back to the year 1648, when the Peace of Westphalia ended Europe's Thirty Years' War and ushered in a new era of international relations. In contrast to the prior norms of empire, the Westphalian order solidified a conception of nation-state sovereignty that guaranteed the following five things: (i) the right to monopolize control of the instruments of violence; (ii) the sole right to collect taxes; (iii) the prerogative of ordering 
the political allegiances of citizens and of enlisting their support in war; (iv) the right to adjudicate in disputes between citizens; and (v) the exclusive right of representation in international society (Bellamy and Williams 2010, 30). These five monopolies, in establishing the Westphalian notion of sovereignty, were intended to combat the power of empire on the continent and effectively constituted a sort of non-interference agreement. Under Westphalian sovereignty, all states were to be considered equal entities independent from one another and abiding by minimal rules of coexistence (Bellamy and Williams 2010, 31); essentially, the peace was a self-determination and "live and let live" agreement between some world powers. However, it is important to note that "Despite the ascendancy of sovereign states... the norms of international society applied only to European - and a small handful of non-European - states. A quite different set of rules applied in the colonized world" (Bellamy and Williams 2010,31). This reveals a hierarchical conception of power built into the modern nation-state at its genesis, where the nation-state is sovereign to the exclusion of other nation-states both over its own citizens, and over colonized lands and people considered neither nation-states nor citizens. Moreover, on the Westphalian model sovereign responsibility is limited to relations with other states, and is not engineered to take into account the treatment of citizens (Bellamy and Williams 2010,36). In other words, it emerges that citizens are more obligated to the nation-state than the nation-state is to them, making modern Westphalian citizenship a fundamentally disempowered status.

As dismal and authoritarian as this picture of citizenship may seem, recent years have ushered in what some identify as a post-Westphalian era. Citizenship, while still tied to the nation-state, is less of a subject status and more of a relationship between 
individuals and their government. For example, documents such as the United States Bill of Rights (which is ever-evolving, but was introduced in 1791), the Canadian Charter of Rights and Freedoms (1982), and the Universal Declaration of Human Rights (1948) affirm basic political and social capabilities that should be guaranteed to all persons. The importance of these documents, whether they are legally binding or not, is in their demonstration of the changing dynamic between citizen and state. The Westphalian principle of non-interference is no longer absolute, but rather depends on the nationstate's fulfillment of responsibilities to its citizens (Bellamy and Williams 2010, 36)responsibilities that are often set out in these charters and declarations. Summarizing the impact of guaranteed rights and freedoms, the post-Westphalian framework as put forward by Francis Deng highlights that "The corollary of sovereignty... is accountability. The host state is made accountable to its citizens, and international society acquires a responsibility to assist that state or, in extreme cases, to act to fulfil its responsibilities to its citizens even without the state's consent" (Bellamy and Williams 2010, 38). However, while post-Westphalian citizenship seems to empower citizens against the nation-state, Bellamy and Williams note that there is malaise about the implications of post-Westphalian sovereignty for global power dynamics. The malaise rests on the idea that post-Westphalian international society is merely a sly way for the Global North to renew its practice of values-imposition on the Global South, thus jeopardizing the self-determination of post-colonial states (Bellamy and Williams 2010, 39). Though the Westphalian system has evolved and matured in its lifetime, we would do well to consider the ways in which the modern nation-state remains based on subjugation and control. Moreover, given that the dynamic between citizen and state has 
changed demonstrably in the post-Westphalian system, the concept of citizenship is due for a corresponding update.

Further to the point of subjugation perpetrated by the nation-state, Tully identifies "two features of modern citizenship — a universal institutional form of citizenship conjoined with a universal set of historical processes that bring it to the non-West under Western tutelage" (Tully 2014, 8). I have discussed the institutional aspects of citizenship above, highlighting citizenship as a legal status granted and maintained by the Westphalian (or post-Westphalian) nation-state. Tully's phrase "Western tutelage" seems to be a nod to decolonization, wherein "After the Second World War the Westphalian order expanded to cover the entire globe, as former colonies sought to take their place as sovereign states" (Bellamy and Williams 2010, 31). Yet decolonization was not always a smooth progression of dependent modernization and citizenization where post-colonial states developed the capabilities and institutions of self-government that had been previously denied to them. Rather, colonization and decolonization have both seen the nation-state use citizenship as tool of oppression. The enfranchisement of Indigenous people in Canada, for example, was not a recognition of political rights but rather part of a program of cultural genocide. Glen Coulthard of the Yellowknives Dene First Nation describes the oppression of Indigenous peoples - and its institutionalization in legal precedents - as being based on the "white supremacist myth that Indigenous societies were too primitive to bear fundamental political rights when they first encountered European powers" (Coulthard 2008, 195). This perception of Indigenous people as somehow unfit for or undeserving of citizenship led the colonial government to attach certain conditions of assimilation to Indian enfranchisement. In exchange for citizenship 
and the right to vote, Indigenous people were expected to "abandon Indigenous identity and communal society... in order to merge with the 'free,' individualistic and nonAboriginal majority" (McCardle 2014).

Voluntary enfranchisement, however, was rare. Eligible candidates for enfranchisement were Indigenous men of at least age twenty-one, "of sober and industrious habits", who were debt-free, spoke either French or English, and were either educated or deemed "sufficiently intelligent to be capable of managing his own affairs" (Gradual Civilization Act 1857). There was also a three-year probationary period after examination by a Commissioner before citizenship was actually granted. Instead of this gruelling and demeaning voluntary process, many Indigenous people lost their status and became forcibly enfranchised either through extended absence from reserves, attendance at a university, service in the military, or - in the case of Indigenous women — marrying non-Indigenous men (Crey 2009). Canada also had a residential school system which removed Indigenous children from their parents and educated them in the colonial way of life — often enforcing the desired behaviour with relentless physical and sexual abuse.

The Truth and Reconciliation Commission of Canada has found that through the enfranchisement program and general treatment of the Indigenous population, the nationstate has engaged in cultural genocide against Indigenous people:

States that engage in cultural genocide set out to destroy the political and social institutions of the targeted group. Land is seized, and populations are forcibly transferred and their movement is restricted. Languages are banned. Spiritual leaders are persecuted, spiritual practices are forbidden, and objects of spiritual value are confiscated and destroyed. And... families are disrupted to prevent the transmission of cultural values and identity from one generation to the next. (Truth and Reconciliation Canada 2015, 1) 
This is what enfranchisement and institutional citizenship meant to the Indigenous communities of Canada - a price that nobody should be made to pay for recognition of their fundamental political rights.

The history of citizenization thus shows that the conditionality of citizenship status can be and has been used to subjugate and disempower colonized populations. Citing the work of Franz Fanon, Coulthard reminds us that "in contexts of domination such as colonialism... the terms of recognition [are] usually determined by, and in the interests of, the colonizer" (Coulthard 2008, 191). While recognizing and honouring the fact that Indigenous populations were uniquely and gravely affected by recognition via institutional citizenship, I propose that Fanon's argument can be extended to illustrate the function of institutional citizenship more generally. That is to say: in institutional citizenship, the nation-state defines the terms of recognition, and those terms often reflect the nation-state's interests. This is abundantly clear in the original Westphalian formulation of citizenship, which guaranteed few (if any) rights and focused primarily on the sovereign's interests - taxation and militarization. Though post-Westphalian norms of nation-state accountability have complicated and obscured the ways in which institutional citizenship continues to oppress, the conditionality of citizenship status still puts many populations in a socio-politically disadvantaged and precarious position. This is evident in the discourse of legal/illegal in American citizenship, as discussed by Katarzyna Marciniak. Marciniak explores anti-immigrant rage and activism to expose the inconsistencies — even hypocrisy—in conceptions of citizenship that rest on distinctions of legal/illegal. Given that legality/illegality is a designation bound up in the institutions 
of the nation-state, I take the notion of citizenship Marciniak works with to be similar to modern institutional citizenship as I have discussed it thus far.

Drawing on her own experience as an immigrant from communist Poland, and the experience of a friend whose immigration was handled almost entirely by the educational institution to which she was transferring, Marciniak contends that "the legalization process may be a relatively easy exercise in cosmopolitan mobility, if only for the select ethnically desirable newcomer." (Marciniak 2013, 261-262). Through an analysis of "digital rage", or online anti-immigrant activism, Marciniak finds that "raging against the 'illegals' is mainly directed at a specific class of Mexicans (and Latino/as in general) as well as Arabs and other nonwhite newcomers from economically disadvantaged or 'failed' states" (Marciniak 2013, 265). Mexican and Latino immigrants in particular occupy "a profoundly ambivalent position in the U.S. economy as they are... simultaneously wanted and unwanted, welcomed and unwelcomed, as labor that is cheap and disposable" (Marciniak 2013, 265). It is this observation that I find most salient in the discussion of institutional citizenship as an expression of the interests of the nationstate and the resulting precarious position of immigrant populations. The labour of nonwhite immigrants, "legal" or otherwise, is evidently needed and exploited in the economy, while at the same time challenging America's legitimacy and self-concept. The "anxious performance of domination", as Marciniak calls it, contained in anti-immigrant rage belies the insecure position of institutional citizenship and "legality" itself. Assertions of legality entail an implicit "claim to an unquestioned rightful ownership of the nation and a complete erasure of Native Americans as if 'our common heritage as Americans' has always legitimately and solely belonged to a postcolonial imaginary" 
(Marciniak 2013, 267). Nonwhite newcomers do not fit into this "common heritage" and are socially constructed as "other"- and in the context of citizenship, "illegal"— despite, in many cases, having gone through the prescribed institutional procedures. Whereas institutional status is not immediately discernable, the visuality of ethnicity enables a performance of legality wherein the dominant members of American society can reaffirm their legitimacy and supremacy. In other words, non-citizenship status (either perceived or real) can be and has been used to mark people for disadvantage and marginalization both socially and economically beyond the formal rights and responsibilities of citizenship.

In opposition to this rhetoric, Elie Wiesel—a Holocaust survivor, writer, and Nobel Peace Price winner-once said of immigration that no human being is illegal. Wiesel's comment is a poignant reminder of the function of institutional citizenship in constructing a nation-state's sociopolitical landscape. "No human being is illegal" deconstructs the way in which legal status in the form of institutional citizenship is hyperbolically extended to encompass the legitimacy of the person —a rhetorical tactic with divisive and devastating effects for immigrant and racialized populations. To highlight the inappropriateness of the legal/illegal discourse, Marciniak points to the work of the Centre for the Study of Political Graphics and their organization of a traveling art exhibition operating under the title "No Human Being Is Illegal". The exhibition consists of a variety of posters that "[counter] the prescribed visuality of illegality by exposing the U.S. citizenship itself as 'illegal' - rooted in the colonization of indigenous people and in neocolonizing practices of exploitation" (Marciniak 2013, 272). Setting aside the legal intricacies that would definitively support such an argument, the 
broader point made by the exhibition stands: through its history of colonization, exploitation, and exclusive concepts of belonging, citizenship and the rhetoric surrounding it are used to disadvantage "othered" populations in ways that include and surpass the simple lack of citizenship-guaranteed rights.

There is obvious anger and rage contained in anti-immigrant sentiment, particularly of the sort that Marciniak discusses. Yet there may be another emotion at play that explains why nonwhite immigrants are excluded from the American "common heritage" and citizenship: disgust. According to Martha Nussbaum, "Disgust is a strong aversion to aspects of the body that are seen as 'animal reminders' - that is, aspects of ourselves that remind us that we are mortal and animal... The core idea in disgust is that of (potential) contamination through contact of ingestion: if I take in what is base, that debases me" (Nussbaum 2016, 48). Disgust has an evolutionary purpose in this way, meant to protect us from disease, and so is usually directed at materials such as excrement, other bodily fluids, decay, things with foul odours, and the like. When confronted with rotting food, for example, a disgust reaction disinclines us to ingest the food and thus protects us from contamination and illness. However, in a perversion of the disgust reaction, "disgust properties are projected onto groups of humans who do not really have those properties: racial, sexual, religious, or caste minorities are portrayed as hyperanimal or hyper-bodily, and are then said to be contaminants" (Nussbaum 2016, 48). Follow-through in this inappropriate extension of disgust can have devastating social and political consequences: one need only remember the doctrine of "separate but equal" and the depravity of racial segregation not just in America, but all over the world, to see the havoc that this abstracted form of disgust can wreak. Nussbaum describes these 
segregation practices as "remarkable rituals of contamination-avoidance, policing the boundary between the dominant group and the animal" (Nussbaum 2016, 48).

Importantly for our discussion of citizenship, Nussbaum points out that "Disgust does not exactly involve the idea of a wrongful act, but blame often creeps in: the contaminating person or group is resented for daring to claim space, or to contact the self-insulating person or group" (Nussbaum 2016, 49). I take this sort of disgust to be operative in antiimmigrant rage and the discourse of legal/illegal. A nonwhite immigrant having the nerve to occupy space in white America is unjustifiable and downright unconscionable to some, based on anything from unconscious bias to an outright racist worldview. The dark, the dirty, the animal, the bodily are unfit for citizenship and would constitute a contamination of the public sphere.

This aversion to feeling and the bodily is also evident when liberal impartiality is applied to the political process. Specifically, liberal impartiality has a filtering effect wherein citizens' particularities are constructed as private and therefore excluded from public life. However, while disgust reactions may obtain in this case, the salient issue is less one of disgust and more one of universalizability. The bodily realm indicates feeling, particularity and partiality, immediate personal needs and concerns, and so the demand for universalizability in the public sphere is an attempt to "reduce the plurality of moral subjects and situations to a unity by demanding that moral judgment be detached, dispassionate, and universal" (Young 1990, 102). While the motivation for liberal impartiality in this form is ostensibly to formulate norms and policy that are abstracted from any particular set of interests and are therefore acceptable and applicable to most reasonable people across categories of difference, the effect of liberal impartiality is the 
creation of a universal category "which requires expelling those aspects of the different things that do not fit into the category" (Young 1990, 102). It is by this mechanism of homogenization that swaths of the population are excluded from full participation and consideration in democratic processes and public reasoning essentially on the basis of having needs and interests. It is merely because their particular needs and interests are less common that they are deemed partial—too narrow in focus and applicability—and therefore inappropriate for inclusion in public space. On the other hand, the needs and interests that are common to many are viewed as impartial and more widely applicable perhaps due to sheer volume. This leads to a construction of that particular set of interests as universal—when really, universality is a flawed inference from sheer volume. The dichotomy between reason and feeling thus manifests as a dichotomy "between a public authority that represents the general interest, on the one hand, and private individuals with their own private desires, unshareable and incommunicable" (Young 1990, 103).

This division and its embodiment in democratic institutions is untenable for two reasons. The first, mentioned already, is that liberal impartiality's demand for the exclusion of particular needs and interests from public life results in the limited consideration and participation of certain groups in the democratic process. Nation-state institutions already regulate the ways in which citizens may participate in public life, and even then, citizens' participation and the uptake it will secure in the impartial public realm hinge on the exclusion of what may be the most definitive aspects of their experience as citizens:

The modern conception of the public... creates a conception of citizenship which excludes from public attention most particular aspects of persons. Public life is supposed to be 'blind' to sex, race, age, and so on, and all persons are supposed to 
enter the public and its discussion on identical terms. This conception of the public has resulted in the exclusion of persons and aspects of persons from public life. (Young 1990, 120)

What liberal impartiality fails to take into account - or outright rejects - is that when people have feelings and desires it is often not a strictly personal matter. Recalling the feminist slogan "the personal is political", we may see that feelings and desires of a certain sort (i.e. feelings and desires about public life, not specific feelings and desires such as the desire for a sandwich for lunch) are often at their core a sort of social justice claim that should be debated democratically. Young argues, "When people say a rule of practice or cultural meaning is wrong and should be changed, they are usually making a claim about social justice" (Young 1990, 9). If the claim about a rule of practice or cultural meaning is rooted in someone's experience of that rule or meaning based on their sex, race, age, or other "particular set of interests", then this is an important factor to consider.

The second reason that a public life based on liberal impartiality is untenable is because what impartiality demands of us is simply impossible. Due to our inherent situatedness and relationality as human beings, Young argues "No one can adopt a point of view that is completely impersonal and dispassionate, completely separated from any particular context and commitments" (Young 1990, 103). Again, it is not the case that the "impartial" point of view is separated from particular context and commitments. Rather, the majority point of view is constructed as having some sort of universal truth and applicability because of the very fact that it is the majority point of view: most people see merit and their interests protected therein. Young's point about situatedness calls to mind the saying "You can't see the picture when you're in the frame"- that is, if your interests 
are common enough as to be in a majority, it is easy to see that interest as universal when in reality it is still situationally and relationally bound.

To summarize, my discussion of modern citizenship as an institutional status has been intended to demonstrate that "the state institutional and discursive fields... are by no means neutral; they are profoundly hierarchical and power-laden" (Coulthard 2008, 197). In particular, institutional citizenship with its history of colonization and the marginalizing "democratic" structures of representative democracy—reliant on liberal impartiality_-is a citizenship that is exclusive and disempowered/depoliticized. Liberal impartiality's casting of the interests of the majority as properly universalizable is troubling and untenable. Given this, we must critically assess any concept of citizenship that relies on these institutional and discursive fields - particularly given the way liberal impartiality demands the erasure of differences between persons. Marciniak's work contributes to this assessment by establishing that the "supposedly lucid rhetoric of (il)legality hides the implicit racial and ethnic hierarchy of immigrant 'illegal' identities" (Marciniak 2013, 265). Young's work on impartiality takes on the very idea of "lucid rhetoric", challenging accepted notions of what is appropriate and valid to be included in public life and civil society. Ultimately, there are three reasons to be wary of a global citizenship that relies on an expanded notion of institutional citizenship:

1) The conditionality of citizenship status can be and has been used to subjugate colonized populations.

2) Non-citizenship status, either real or imagined, can be and has been used to mark people for disadvantage beyond the formal rights and responsibilities of citizenship — socially, politically, and economically. 
3) Liberal impartiality, as a component of institutional citizenship, suppresses the particularities of citizens and makes the interests of the majority or dominant group seem universal.

These three reasons serve to challenge not citizenship as a concept, but liberal conceptions of institutional citizenship. Citizenship itself is an important concept because it speaks to the intersection of moral community and political community, dealing both with what people value and with public collective actions people take based upon those values. My argument in this section has demonstrated that in order to avoid global replication of the harms of institutional citizenship and of liberal impartiality, we cannot simply modify our current understanding of citizenship with cosmopolitanism and call it "global citizenship". Instead, we must humanize and socialize these concepts to make them more sensitive to the salient aspects of persons, before we combine them in a conception of cosmopolitan global citizenship. Given the use of impartiality in concepts of citizenship and cosmopolitanism alike, developing an inclusive impartiality will allow us to correspondingly construct an acceptable notion of global citizenship that deals with global issues while being acceptable to a global public, without appealing to an oppressively homogenizing sense of universalizability. In the next section, I turn to the literature on human capabilities to address this difficulty.

\subsection{Inclusive Impartiality}

In this section, I undertake a capabilities-focused restructuring of liberal impartiality. The capabilities approach is a lens through which we can assess impartialism in public reason, and the goal of humanizing impartialism with the capabilities approach is to make it better able to accommodate the challenges it faces in practice. According to current 
norms of liberal impartiality, the private and the public are two separate spheres. As a challenge to the division of liberal impartiality, I deploy the capabilities approach and its encouragement that we consider first and foremost what people are able to do and to be. If this question is the center of public reason, and we construct civic worlds around answering it, then this encourages the broadening of public discourse in a way that welcomes previously marginalized populations and concerns - thereby humanizing and globalizing impartiality. Moreover, the capabilities approach contains the building blocks for societies to determine what is universally important for flourishing, but in a way that refrains from homogenizing and erasing difference. The inclusive impartiality that results from this capabilities-focused analysis will be crucial to a good practice of cosmopolitan global citizenship.

The capabilities approach is a theoretical framework for justice and human development, pioneered by Amartya Sen and Martha Nussbaum. I will be working primarily with Nussbaum's account of the capabilities approach, which differs from Sen's in subtle but important ways. Nussbaum's capabilities approach yields a partial account of basic social justice and appeals to the concept of human dignity. Nussbaum also proposes a list of ten central capabilities - a task from which Sen refrains. However, both versions of the approach have shared contours and guiding concepts, and the capabilities approach can be seen as "a single, relatively unified approach to a set of questions about both quality of life and basic justice" (Nussbaum 2011, 20). Capabilities refer to what people are able to do and to be, and these states of doing and being are called functionings. The relationship between the two is that capabilities indicate having access to valuable and worthwhile functionings. Capabilities, however, are "not just 
abilities residing inside a person but also the freedoms and opportunities created by a combination of personal abilities and the political, social, and economic environment" (Nussbaum 2011,20). This is what Nussbaum refers to as combined capabilities, as opposed to basic capabilities which are "innate powers that are either nurtured or not nurtured" (Nussbaum 2011, 23). Together, basic capabilities and combined capabilities paint a picture of human development by illustrating what tools for flourishing people have available to them, and what chances they have to put those tools to use. My discussion will pertain mostly to an assessment of combined capabilities, since I take marginalization by liberal impartiality to rest on contextual sociopolitical factors rather than on a particular demographic's fundamental lack of capacity.

Nussbaum describes the orientation of the capabilities approach in a few characteristics. First, it takes each person as an end, "asking not just about the total or average well-being but about the opportunities available to each person" (Nussbaum 2011, 18). This is an important contribution for our analysis of liberal impartiality because it allows us to delineate between what is supposed to be available to people, or what is generally available to most people, and what people are actually able to achieve within that general availability. Taking each person as an end demands that we distinguish between basic and combined capabilities as described above. For instance, someone not mindful of capabilities may assess the norms of public reason from within the vacuum of theory, accepting the "view from nowhere" argument for universalizability and concluding that liberal impartiality is an acceptable principle around which to structure public reason. After all, liberal impartiality is intended to guarantee a place for all in public reason and ensure that no particular set of interests dominates. What could be 
objectionable about that? Yet this conclusion ignores the way that impartiality functions to marginalize rather than to equalize when it interacts with people's social, political and economic realities. The capability-minded person, in contrast, will be attentive to these realities and to people's functionings and capability sets. In the case of liberal impartiality, a relevant observation may be that "Many people who are internally capable of participating in politics are not able to choose to do so in the sense of combined capability" (Nussbaum 2011, 22); that is, they have within them the capacity to participate but are unable to realize that capacity given the rules of the game. This misfire is of importance to the capabilities theorist who is concerned not just with human development overall, but with each individual's possibilities for flourishing and how systems support or hinder that. Taking each person as an end is thus an important step in the humanization of impartiality, making it attentive to those whose flourishing "slips through the cracks" of generalizations and aggregate measurements.

The second characteristic of the capabilities approach that Nussbaum stresses is that it is focused on choice or freedom, "holding that the crucial good societies should be promoting for their people is a set of opportunities... which people then may or may not exercise in action: the choice is theirs" (Nussbaum 2011, 18). The capabilities approach asks us to consider in broad terms what kinds of things we generally think each one of us should be able to do and to be. Nussbaum's list contains ten suggestions of such central capabilities. These central capabilities, whatever they are, are what society needs to provide for its citizens to pursue their flourishing to the fullest. But the approach's commitment to choice and freedom ensures that each person is able to pursue their flourishing as they see fit. Nussbaum's list, therefore, is not a call for each person to 
aggressively pursue each particular capability on that list. Rather, it is an assertion that those ten capabilities (and perhaps other ones, too) are fundamentally important to flourishing, in a variety of ways and for a variety of reasons. It may be that someone does not particularly value play, for instance, and their flourishing does not include functioning in accordance with that capability. However, it must be ensured that they could pursue play should they wish to - the capability obtains, regardless of the functioning. Nussbaum further emphasizes the freedom and choice aspect of the capabilities approach with the distinct but related stipulation that the approach is "resolutely pluralist about value: it holds that the capability achievements that are central for people are different in quality, not just in quantity" (Nussbaum 2011, 18-19). This once again recognizes that flourishing means different things for different people, and that while capabilities should be universal in applicability they are anything but one-sizefits-all. These aspects of the capabilities approach contribute to the humanization of impartiality by taking to task the homogenizing universalism of impartiality's liberal underpinnings. A capabilities-based critique of liberal impartiality questions whether, under impartialist norms, people are really free to choose the pursuits that matter to them.

The penultimate characteristic of the capabilities approach mentioned by Nussbaum is the one that most closely ties it to the project I undertake here. The capabilities approach is "concerned with entrenched social injustice and inequality, especially capability failures that are the result of marginalization or discrimination" (Nussbaum 2011, 19). This factor describes why the capabilities approach is appropriate to apply to liberal impartiality. If liberal impartiality contributes to a form of social injustice and inequality that is both a result and a catalyst of marginalization, it is 
precisely the sort of system that the capabilities approach is designed to challenge. Finally, as an outgrowth of this concern with entrenched social injustice and inequality, the capabilities approach "ascribes an urgent task to government and public policynamely, to improve the quality of life for all people, as defined by their capabilities" (Nussbaum 2011, 18-19). It is this task to which I hope my project contributes. The capabilities approach humanizes international development, recasting it as human development and encouraging us to conceive of poverty not in terms of finances but in terms of freedoms. Taking all people's wellbeing seriously requires taking account of their diversity, not just of their resources and the distribution thereof. This is because "Differences in age, gender, special talents, disability, proneness to illness, and so on can make two different persons have quite divergent opportunities of quality of life even when they share exactly the same commodity bundle" (Sen 1999, 69). Wellbeing is determined by more than just resources, because people deal with different demands on their resources based on particular aspects of their person.

So, by asking us to consider people's real opportunities to act—-their combined capabilities - the capabilities approach brings into focus the dissonance between what impartiality is intended to accomplish and what it actually accomplishes. A capabilitiesfocused analysis of public reason and civic spaces holds that "Developing policies that are truly pertinent to a wide range of human situations means attending to diverse factors that affect the quality of a human life — asking, in each area, 'What are people (and what is each person) able to do and to be?"' (Nussbaum 2011, 14). This prescription to attend to diverse factors that affect quality of life is directly at odds with the objectivity and division of public and private mandated by liberal impartiality. Held, for example, 
discusses impartiality in its capacity as "reasoning from the point of view of others" (Benhabib 1992, cited in Held 2010, 46) and points to Rawls' original position as a thorough explication thereof. But when the original position has us step behind the veil of ignorance, erasure of particularities becomes the primary means of conceptualizing fairness. Furthermore, if the motivation for impartiality (particularly in cosmopolitanism) is to "[specify] rules and principles that can be universally shared" (Held 2010, 47), then a "view from everywhere" will work better than a "view from nowhere"- both because the former is actually possible and acknowledges the inherent relationality of humanity where the latter does not, and because it solicits and includes important factors that affect people's combined capabilities. Universal moral principles need not necessitate the erasure of difference. Rather than abstracting from any set of interests at all, better to think about what is acceptable to a multiplicity of interests. Moreover, casting these "interests" in terms of capabilities and flourishing - the pursuit of which is truly common to all—provides a shared framework and justification in public reason. Nussbaum explains that "human dignity, from the start, is equal in all who are agents in the first place... All, that is, deserve equal respect from laws and institutions. If people are considered as citizens, the claims of all citizens are equal." (Nussbaum 2011,31). And, where impartiality demands that citizens' claims be treated with moral principles acceptable to all, we consider capabilities and flourishing.

There is, therefore, at least one way in which the capabilities approach can work to humanize impartiality. Following impartiality's stipulation that all claims enjoy "treatment based on principles upon which all could act" (Held 2010, 46), the capabilities approach helps formulate those principles by pointing to the kinds of things that impartial 
treatment needs to protect and support, given that each person's flourishing matters equally. Granted, the capabilities approach itself is not a comprehensive moral theory. It does not entail conceptions of the good, it is pluralist about value, and it is deliberately underspecified to allow for situational variation and adaptation (in Sen's version, at least-Nussbaum charges ahead with her list, undeterred). The point is that the question "What is each person able to do and to be?" is an excellent place to start the project of a theory of fundamental political entitlements, and by enumerating the opportunities that are important to flourishing and a good life, we can extrapolate some normative claims. I therefore propose the use of contextually specified versions of the capabilities approach as the basis for impartiality — a yardstick for equal treatment of citizens' claims. To explain: impartiality requires that we do not privilege the interests and wellbeing of any particular group above others. In order to do this job well, we need a way to compare the (dis)advantages that some people face. The capabilities approach is designed for precisely such a comparative purpose, providing a way to assess wellbeing that builds on the diversity of human beings and their needs. The capabilities approach humanizes impartiality by assessing not what is fair all other things being equal, but what is fair given that all things are decidedly not equal.

I emphasize that a humanized impartiality based on the capabilities approach as I have described above is entirely compatible with Held's layered cosmopolitanism, in place of his somewhat confusing reliance on liberal impartiality. Indeed, undertaking a capabilities analysis in any given society seems to be exactly the kind of process Held advocates when he asserts that his account of cosmopolitanism takes cultural and political specificity seriously. "Universal moral principles play a defining role," Held 
acknowledges, "yet the hermeneutical necessity of interpreting their precise meaning in the local settings in which they operate is recognized" (Held 2010,16). The capabilities approach is a mechanism by which universal moral principles and their precise meanings can be determined, discussed, and modified. Indeed, this is the task eternal: Held follows Gadamer in acknowledging that the job of cosmopolitanism is never done, that the impartialist reasoning at its core takes shape in "a theoretical dialogue that is always open to fresh challenge and new questions" (Held 2010,48). The capabilities approach meets this head on, providing us with the concepts and tools to elucidate both the diversities and the universalities of human experience — political and moral—in a way that is inclusive of everyone's striving for a good life.

Having humanized impartiality and thus strengthened our concept of cosmopolitanism, I will now say a little bit about what a correspondingly humanized concept of citizenship looks like. The idea of global citizenship-as-praxis, based on Tully's diverse citizenship, makes great strides towards remedying some of the issues with institutional citizenship as outlined in the previous section (pg. 27-28). In particular, it humanizes citizenship in the way that the capabilities approach humanizes impartiality— by removing the focus from the beings and doings of institutions, and focusing on the beings and doings of citizens themselves. Defining citizenship as activity rather than as status sidesteps the issue of the nation-state's changing role and importance in global relations. In whatever capacity that institutional citizenship may be outmoded, diverse citizenship avoids the quagmire altogether because it is not dependent on institutions. Citizens as moral agents will never cease to be relevant to, or cease to be a part of, political communities - citizens are both the means and the end of politics. 
Diverse citizenship recognizes this and correspondingly places the onus of citizenship on citizens themselves.

Tully acknowledges that institutions can and do still play a part in this landscape, conceding that "Civic activities - what citizens do and the ways they do them - can be more or less institutionalized and rationalized (in countless forms), but this is secondary. The primary thing is the concrete games of citizenship and the ways they are played" (Tully 2014, 35). There is a sort of plug-and-play approach in institutional citizenship, where individuals are thrust into a pre-existing game of citizenship and given parameters for participation. Tully's statement above highlights that in diverse citizenship, citizens themselves choose the game, set the rules, and exercise their right to play. It is a much more empowering and agent-centric approach. On the diverse account, if citizenship exists then it entails that citizens are actually out there doing citizen-things. A praxis of citizenship allows and indeed necessitates that citizens constantly construct and reconstruct their normative order rather than being passive subjects in it. By definition, if citizenship is a praxis, then citizens practice; citizens are self-appointed and self-defined.

The empowered self-determination of citizenship-as-praxis ensures that all people are able to do the same things with their citizenship, both in quality and quantity. Given that institutions are biased against certain groups, and given the way that public discourse it set up to marginalize certain sets of concerns as outlined above, institutional citizenship based on liberal impartiality means that some people may be able to do more with their citizenship than others. However, once again, by abstracting citizenship and the activities that are at its core from the institutions which regulate them, we allow citizens to move in a much more liberated and equitable discursive space. Citizens are defined by what they 
do, not by what institutions say they can do. This is particularly important with respect to the arguments advanced by Coulthard and Marciniak. Coulthard raises the issue that the terms of recognition (citizenship or otherwise) are often set by the colonizer, and serve the colonizer's interests. On the diverse account of citizenship, terms of recognition are moot because citizens set their own terms. The acts of resistance that indigenous populations have been engaging in, quietly and otherwise, for decades can be validated in the diverse tradition as political participation in its truest sense: as a praxis of citizenship, even in the face of institutions that would seek to minimize and restrict it. Similarly, the self-determination of praxis-based citizenship undermines the problematic legal/illegal discourse that Marciniak takes to task. Diverse citizenship judges people and their belonging not by their ethnicity, but by their undertaking of political activity. This gets to the heart of the refrain "no human being is illegal". There is no wrong way to be(come) a citizen on the diverse account, because one only is a citizen insofar as one does citizenship. To reiterate in detail:

Whereas modern citizenship focuses on citizenship as a universalizable legal status underpinned by institutions and processes of rationalization that enable and circumscribe the possibility of civil activity (an institutional/universal orientation), diverse citizenship focuses on the singular civic activities and improvisations of the governed in any practice of government and the diverse ways these are more or less institutionalized or blocked in different contexts (a civic activity/contextual orientation). (Tully 2014, 8-9).

The last thing I will point out before moving on is that the contextual orientation of diverse citizenship is also important, in that the institutionalization or blocking of civic activity is part of the focus and perspective. This indicates a background concern for structural injustice — highly compatible with the aims of the capabilities approach—and which will be discussed at length in the next chapter. 
To summarize, while the capabilities approach humanizes impartiality, reconceptualising citizenship as a praxis helps to humanize citizenship independent of its connection to impartiality. This is because it sees the citizen as an individual as the locus of citizenship, and freeing them from institutional limitations means that there are less to no external limitations governing what they can and cannot do with their citizenship. This praxis-based citizenship combined with a humanized impartiality paves the way for a good practice of cosmopolitan global citizenship. We reject the oppressive history and flawed standards of institutional citizenship, and we reject the tyranny of liberal impartiality in cosmopolitanism and in the institutions of the nation-state. In their stead, we embrace a humanized capability-focused impartiality and an empowered praxis-based citizenship. Taking these two things together, we avoid replicating the harms of liberal impartiality and institutional citizenship globally when we simply modify our current understanding of citizenship with our current understanding of cosmopolitanism. In the next chapter, I will use Iris Marion Young's social connection model to demonstrate how our newly humanized cosmopolitan global citizenship can be socialized, to further increase its sensitivity to difference and global relationality. 


\section{Chapter 2: The Social Connection Model}

In this chapter I will argue that Iris Marion Young's social connection model provides an account of responsibility and relationality that strengthens the praxis of cosmopolitan global citizenship. While the capabilities approach humanizes cosmopolitan global citizenship, the social connection model socializes cosmopolitan global citizenship in that it highlights relationships and obligations, and enables us to work out how to take responsibility for global injustice. The process of reflection and action facilitated by the social connection model is crucial to the praxis of cosmopolitan global citizenship. My argument in favour of this interpretation is fourfold, and largely exegetical. In the first section I discuss Young's understanding of structural injustice, and situate structural injustice as a salient issue in the realm of international development and global equality. In the second section I present Young's notion of political responsibility, which she constructs with reference to the writings of Hannah Arendt. I focus in particular on the contrast between guilt and responsibility, highlighting how each helps or hinders the pursuit of justice and social/structural change. In the third section, I outline the five components of Young's social connection model. In the fourth section, I consolidate my exegesis and show that the social connection model reflects both a cosmopolitan theory of justice and the necessity of active participation in civic society, in a way that is both humanized and socialized. These two components, synthesized and expressed in the social connection model, comprise a comprehensive and applicable account of the praxis of cosmopolitan global citizenship. In the next chapter, I will apply the social connection model — in its capacity as a tool for uncovering the activities of a humanized and socialized cosmopolitan global citizenship — to international service learning projects. 


\subsection{Structural Injustice}

As discussed in the previous chapter (pg. 11), cosmopolitanism lends a distinct justice focus to global citizenship through its framework of responsibility, accountability, and obligations. I now delve into the nature of the injustice that cosmopolitan global citizenship is uniquely suited to address. Specifically, I examine not just isolated instances of injustice but larger global patterns of injustice that are inherent to systems rather than to individual agents. A robust account and understanding of this kind of injustice, and the ways that citizens are entwined in the systems that perpetuate it, is crucial to formulating a plan for the civic activity that constitutes cosmopolitan global citizenship. In what follows, I present a critique of the global economic order that suggests one context in which we may consider our obligations as cosmopolitan global citizens.

A common perception of poverty, both in "developed" countries and elsewhere, is that one's material and economic conditions are a direct reflection of one's abilities, motivation, and willingness to work. That is, poverty is both one's own fault for getting into and one's own responsibility to get out of: "Each must self-sufficiently bear the cost of [their] choices and has no moral right to expect help from others, even if the individual or family should suffer harm or disadvantage" (Young 2011, 10). Young refers to this way of thinking as "the discourse of personal responsibility". She suggests that the discourse of personal responsibility has gained such popularity because it presents an attractive opportunity for absolution —if one lives without imposing on others, either morally or materially, then one is discharged of any responsibility or obligation. However, there are many flaws in this thinking. Mainly, as Young points out, "The 
discourse of personal responsibility fails to acknowledge the many ways that some middle-class and rich people behave irresponsibly... It ignores how the institutional relations in which we act render us deeply interdependent." (Young 2011, 4). In other words, emphasis on personal responsibility above all else encourages us not to acknowledge the myriad ways in which we are relationally linked, and to reject the possibility that we may in fact be implicated in the suffering of others. Moreover, we are implicated not necessarily in terms of individual actions that we are conscious of as producing injustice, but by way of our ostensibly benign collective participation in structural and institutional processes which are themselves unjust — another facet of the problem that the discourse of personal responsibility obscures.

The unjust systemic and institutional processes—-henceforth "structural injustice" in Young's terminology—in question for this discussion are the ones that comprise the global economic order. Young asserts that structural injustice exists "when social processes put large groups of persons under systematic threat of domination or deprivation of the means to develop and exercise their capacities, at the same time that these processes enable others to dominate or to have a wide range of opportunities for developing and exercising the capacities available to them" (Young 2011, 52). To be clear, there are many kinds and instances of structural injustice; for example, Young's chosen structural injustice case study is the struggle to find affordable housing, which is compounded by racist and classist understandings of what constitutes a "safe neighbourhood". As a preparatory step toward my case study in the next chapter, my discussion will center on the global economic order. International service learning tends to be a strategy of the Global North to focus on and address poverty in the Global South. 
This splitting of the Global North and Global South is based on the fact that the global distribution of resources is decidedly asymmetric. Thus I see it as an important part of my project to analyze the way that choices made in the Global North can affect the opportunities that people have in the Global South.

There is a troubling global power dynamic identified by nations in the Global South in the 1990 Report of the South Commission, wherein they make the following observation:

A network of relationships has been built up among private entities- banks, investment houses, transnational companies- in the leading developed countries. This has served to strengthen the influence of decisions made by private bodies on world economic activity, and to that extent to limit the effectiveness of governmental policy decisions. For the South the result is even further marginalization and greater powerlessness. (The South Commission 1990, 5)

This indicates that the global economic order and that international development itself can involve structural injustice, according to Young's criteria: the relationships between private entities in developed countries systematically marginalize and disempower governments in the Global South, while enabling those same private entities and developed countries to dominate the global economy. The world thus emerges as being connected through the global economic order "in an asymmetrical and skewed manner... the relationship is one of dependence much more than interdependence" (The South Commission 1990, 8). This asymmetry and structural injustice is further illustrated in Young's assessment of the global distribution of resources and the system that perpetuates it:

The United Nations Development Program, along with economists like Jeffrey Sachs and Amartya Sen, declare that absolute poverty in the world could be eliminated if only the richest nations were to devote 0.7 percent of their GNP to 
aid for the world's poor. Such aid would be a fine thing if it would be wrested from those countries and put to good use. But even such a massive transfer would not itself change the structural processes in which powerful holders of capital decide where to invest and make deals that keep billions of people working under unjust conditions for wages on which they cannot live adequately, or, worse, which exclude them from any means of livelihood at all. (Young 2011, 148)

Young's focus here not only brings attention to current global distributive inequalities, but also to how those inequalities have been and continue to be producedthrough structural processes and injustice. Indeed, Young is clear that without a focus on structural injustice, immediate remedial measures such as aid through a "massive transfer" will be utterly ineffectual in the long term. While Sachs's and Sen's projection would ostensibly make steps toward equalizing wealth across the world, Young reminds us that distributive inequality — while incidentally unjust — is not actually the locus of injustice. In Justice and the Politics of Difference, Young urges us to move away from what she calls "the distributive paradigm", an approach which "defines social justice as the morally proper distribution of social benefits and burdens among society's members. Paramount among these are wealth, income, and other material resources" but also included are "nonmaterial social goods such as rights, opportunity, power, and selfrespect” (Young 1990, 16). For Young, focusing exclusively on distributive outcomes rather than distributive processes paints a fragmented and incomplete picture of the roots of injustice, thereby hindering any remedial efforts. Critiquing distributive processes involves asking important questions about how much of what things people are realistically able to have and, consequently, what kinds of lives people are able to lead based on those havings. These questions highlight that in cases of structural injustice, the systems that determine the distribution of material resources and nonmaterial social 
goods can systematically benefit certain populations and disadvantage others. This possibility necessitates a deeper analysis than simple descriptive assessments of distributive outcomes.

It is worth noting that Young's resistance to the distributive paradigm is coherent with the humanization encouraged by the capabilities approach to international development, and its focus on what people are free to do and to be. As we recall, capabilities help us assess whether people can lead the kinds of lives they value and have reason to value (Sen 1999, 18). And just as the capabilities approach humanizes impartiality, it also humanizes poverty and development. As Sen explains, “There are good reasons for seeing poverty as a deprivation of basic capabilities, rather than merely as low income. Deprivation of elementary capabilities can be reflected in premature mortality, significant undernourishment (especially of children), persistent morbidity, widespread illiteracy and other failures" (Sen 1999, 20). Importantly, Sen's phrasing pins these negative effects not on simple lack of funds or distributive inequality but on the more general "deprivation of elementary capabilities." For Sen and his capabilities approach, wealth is merely instrumental in allowing people to be and do what they value and have reason to value. This leads Sen to emphasize that wealth is not itself the only or best way to address deprivations of elementary capabilities: "It is as important to recognize the crucial role of wealth in determining living conditions and the quality of life as it is to understand the qualified and contingent nature of this relationship" (Sen 1999, 14). The capabilities approach encourages us to redefine poverty in terms of lack of freedoms while maintaining the importance — instrumental though it may be —of wealth. 
In this way, poverty and structural injustice are humanized and are made about people rather than about money.

Given his reframing of poverty from a wealth focus to a freedoms focus, Sen would likely support Young's statement that "the predominant focus on the distribution of wealth, income, and positions... ignores and tends to obscure the institutional context within which those distributions take place, and which is often at least partly the cause of patterns of distribution of jobs or wealth" (Young 1990, 21-22). It emerges from Young and Sen's critiques that our understanding of injustice and its causes may in fact be drastically flawed, and we may be aiming our metaphorical arrows at the wrong target. Our humanized cosmopolitan global citizenship, however, helps to refocus our attention on the human causes and impacts of injustice in the structures that govern our global economic and social lives. Cosmopolitan global citizenship is well equipped to deal with issues of structural injustice and global inequality. The capabilities approach provides a common language for the problem of global inequality and allows global citizens to formulate people-focused solutions to a problem that is fundamentally about the lives people are able to lead, rather than about the resources people are able to have.

\subsection{Guilt and Responsibility}

Given the enormity and the structural nature of the injustices in which our lives are situated, we may wonder how individual cosmopolitan global citizens can relate to and change a global scheme of processes that feels entirely abstracted from individuals' own choices, actions, and experiences. That is, while both cosmopolitan global citizenship and the injustice it seeks to remedy have been humanized—or put in context relative to people's lives and capabilities—we still need to socialize them. By "socialize" I mean 
that global citizenship must be sufficiently aware of local and global relationality, and pay specific attention to the ways in which these relationships can promote marginalization and disadvantage. Socializing cosmopolitan global citizenship therefore involves recognizing the obligations we have as a result of our relationships, both local and global, and interrogating the ways in which we conceptualize and approach those obligations. A socialized cosmopolitan global citizenship will approach obligations with an attitude of taking responsibility, as opposed to an attitude of guilt, and the social connection model helps facilitate this.

For guidance in moving toward a productive responsibility-based conceptualization of our obligations, I turn to Young's account of what it means to take responsibility in situations of structural injustice. Young makes extensive use of Hannah Arendt's comparison of guilt and responsibility, undertaken in Eichmann in Jerusalem and other texts, due to the comparable circumstances of collective action (or lack thereof) in the face of structural injustice. Working from Arendt's discussions of collective responsibility, Young ultimately presents "a notion of political responsibility as a duty for individuals to take public stands about actions and events that affect broad masses of people, and to try to organize collective action to prevent massive harm or foster institutional change for the better" (Young 2011, 76). It is this notion of political responsibility that I aim to defend as a cornerstone of cosmopolitan global citizenship. Civic activity based on taking responsibility is more fruitful than that based on guilt, and taking responsibility in Young's Arendtian sense is one way that civic activity can turn into a sustained praxis of cosmopolitan global citizenship. 
Collective responsibility and collective action are often assigned according to demarcations of membership. In the case of the Eichmann trial, the collective or membership group in question is a national one - namely, the people of Germany. Reeling from the horrors of World War II and Hitler's Final Solution, and with the exception of the Nuremberg Trials unable to assign blame on the basis of personal responsibility or strict liability, many in Germany and across the world felt intense guilt. Yet Young, paraphrasing Arendt, highlights the inappropriateness of guilt to the circumstance: she asserts, "Expressing a feeling of guilt on behalf of an entire collective, not by virtue of deeds done but by virtue of one's membership in an association, is a sentimental gesture that obscures real political issues" (Young 2011, 77). This is because guilt, in a moral and legal sense, is attributable based only on deeds and their outcomes. An entire group of people cannot be guilty simply by virtue of their membership in that group, though they may feel guilty. Conversely, one does not need to feel guilty in order to be guilty of something. Indeed, for Arendt, guilt "is not a matter of the perpetrator's subjective state; rather, it is an objective consequence of his deeds. It does not matter that Eichmann lacked malevolent intent. He is no monster, but an ordinary, normal person... Eichmann never experienced himself as doing anything wrong" (Young 2011, 82-83). So too, in our discussion, for people who are associated with one another via the global economic order: we as ordinary private citizens may not experience ourselves as doing anything wrong, yet the systems in which we move cause harm with our involvement. In addition to the near irrelevance of feelings of guilt in situations of structural injustice, fault-finding is counterproductive due to its isolating and backward-looking focus. That is, "The harm or circumstances for which we seek to hold agents responsible 
is usually an isolatable action or event that has reached a terminus... the primary purpose of assigning responsibility under this model is to identify the specific culprits or liable parties who should make restitution for the harm" (Young 2011, 108-109). This means that the harm is both decidedly in the past and that it can be causally linked to one or a few individuals who in turn must make amends. In cases of structural injustice, however, the harm is often ongoing and is committed by no-one yet compounded by everyone. How, then, are we to locate the harm and the responsible parties? The answer lies, perhaps perversely, in membership. By “membership" I mean identification with/participation in a system that allows or facilitates injustice, rather than membership in a particular group that actively commits injustice. On the latter account of membership, any German citizen who was not a member of the Nazi party could be considered absolved of responsibility—which is exactly the kind of denial of relationships to injustice that Arendt is trying to counteract. This denial is where the gap in assigning responsibility often plays out, facilitated in part by the way guilt encourages direct liability/causal concepts of responsibility. Stressing membership as a criterion for responsibility helps fill this gap in cases like structural injustice, where direct liability and causality are not easily established. While, as outlined above, membership cannot be a criterion for guilt, it is still salient in that "the sins of our fathers have a continuing effect, and inasmuch as we belong to a political community continuous with theirs, we have responsibility for them" (Young 2011, 78). It would seem that, as opposed to a liability model of guilt that takes people to task for harmful actions, the harm we collectively inflict in cases of structural injustice is through inaction. Though we as a collective therefore cannot be guilty by virtue of our actions, we can still be held responsible by 
virtue of the fact that we are "aware moral agents who ought not to be indifferent to the fate of others and the danger that states and other organized institutions often pose to some people" (Young 2011, 92).

Given that models of guilt are not viable options for dealing with structural injustice, we now ask what taking responsibility entails. In her discussion of guilt and responsibility in World War II and the Eichmann trial, Arendt identifies four categories of relationships that agents may have had to the mass murder of the Jews: 1) those who are guilty of crimes, 2) those who are not guilty of crimes but who bear responsibility by virtue of participating in the society and/or passively supporting the guilty, 3) those who took action to distance themselves from the wrongs, and 4) those who publicly opposed or resisted the wrongful actions (Young 2011, 81). I will now seek to apply these categories to a discussion of systemic injustice in the global economic order and international development. The first category of guilt by virtue of criminal actions has been dispensed with above, given that the harms inflicted by and through the global economic order are not causally linked to any particular individual or group of individuals (though some powerful groups, like the ones gestured at in The South Commission's statement, may bear greater responsibility than the average citizen). The second category is of greater importance to this discussion because it expresses widespread contemporary attitudes towards global poverty and structural injustice in the economy - awareness of injustice tempered by a passive indifference, due to a perceived lack of causal connection that stems from lack of individual wrongdoing. Arendt's description of this group's role in the Holocaust is damning, highlighting the fact that "while they did not do anything to contribute to the crimes, they also did nothing to 
protest them, and persisted in pretending that the events around them were normal and acceptable" (Young 2011, 87). Young describes this circumstance as "political responsibility not taken up", encapsulating that people to some degree acknowledge the existence of a harm while refraining from acting against it. This is perhaps an instance of obligation recognized but refused.

Arendt's third and fourth categories describe what happens when people turn from passive indifference to principled action. The third category, wherein people take action to distance themselves from the wrongs, refers to instances in which individuals are absolved from blame or responsibility through their morally praiseworthy actions as private individuals. Young cites Arendt's examples of academics who gave up their positions rather than swear an oath to Hitler, and those who assisted Jewish friends in hiding or fleeing. An analog to this kind of private praiseworthy action concerning structural injustice in the global economy would be consumers who choose to buy fair trade products and support independent businesses, rather than spend their money on companies who outsource production to sweatshops. Actions like these are certainly principled and intended to send a political message, but still remain in the private sphere of individuals. These kinds of actions are fully realized in Arendt's fourth category of relationships when they become public and collective, thereby morphing into political responsibility. For Arendt, responsibility is political only when it "involves the active participation of citizens, rather than being merely the expression of the interests or wishes of state officials in their bureaucratic functions. To be political, an action must be public, and aimed at the possibility or goal of collective action to respond to and intervene in historic events" (Young 2011, 89). It is important to note Young's clarification, based on 
her reading of Arendt's "Collective Responsibility" as well as Eichmann, that political responsibility need not already be collective. Individuals and small groups qualify as taking political responsibility when their actions are aimed at inciting others' awareness and participation - the collective nature of political responsibility lies there, rather than in raw numbers. Taking political responsibility, as opposed to guilt, reflects follow-through on a recognized obligation and, moreover, an effort to incite the same recognition and action in others in the moral political community. This is the level at which cosmopolitan global citizens should aspire to operate as the fullest realization of their praxis of a public, humanized, and socialized approach to injustice—structural or otherwise.

\subsection{The Five Components}

As a natural progression from Young's notion of political responsibility, I turn to her social connection model to illustrate how it is that we might understand and go about discovering our obligations and consequently taking political responsibility. In this section I will show that the social connection model is congruent with a humanized and socialized cosmopolitan approach to development. Young created the social connection model in order to address the question of how agents, both individual and organizational, should think about their responsibility and obligations in relation to structural injustice. This line of inquiry is key to the praxis of cosmopolitan global citizenship, and indicates special utility for the social connection model in pursuit of global citizenship. Extending Arendt's levels of responsibility into a discourse that highlights and assigns obligations, Young summarizes the social connection model as finding "that all those who contribute by their actions to structural processes with some unjust outcomes share responsibility for the injustice... Being responsible in relation to structural injustice means that one has an 
obligation to join with others who share that responsibility in order to transform the structural processes to make their outcomes less unjust" (Young 2011, 96). This obligation to transform structural processes is designed to fill the gap created by our reliance on holding people responsible through guilt, which is insufficient to deal with the scale and causal complexity of structural injustice. Young stresses the need for the social connection model or something like it in these cases "because the specific actions of each cannot be causally disentangled from structural processes to trace a specific aspect of the outcome. Presumably none intended the outcome, moreover, and many regret it. On my view, this means not that they should not be found responsible, but that they ought to be held responsible in a different sense" (Young 2011, 100). The social connection model builds on the Arendtian recognition of relationships to structural injustice, assigning obligations based on these relationships and thereby holding people responsible. There are five components to the social connection model that accomplish this: non-isolation, judging background conditions, a forward-looking focus, emphasis on shared responsibility, and the prescription that this responsibility can only be discharged through collective action.

The non-isolating aspect of the social connection model addresses the inadequacy of the practice of finding guilt, blaming, or finding fault in taking people to task for the large-scale collective harms of structural injustice. Young does not denounce this practice of isolating altogether. Rather, she explains that these models are intended "to focus on particular agents in order to sanction or demand compensation from them and them alone. It is important to the system of moral rules and legal accountability that all agents know that they may face accusation or be called to account as individual agents" (Young 2011, 
105-106). Isolating is thus important in particular contexts where someone has done an actionable harm, but the lack of actionable harm in cases of structural injustice does not—and indeed, cannot—mean simply that nobody at all is responsible. Young describes how people who produce and reproduce structural injustice "are usually minding their own business and acting within accepted norms and rules" and insists that they bear responsibility without being specifically at fault by virtue of having "contributed to unjust outcomes through their action within accepted institutional rules" (Young 2011, 106). As morally aware agents, and as cosmopolitan global citizens, it is our responsibility both to recognize that these accepted institutional rules create unjust outcomes, and to take up our aforementioned obligation to transform them. Non-isolation contributes to the socialization of cosmopolitan global citizenship by stipulating that the approach to addressing structural injustice is inherently relational and collaborative.

The critical assessment of accepted institutional rules may come about through the second component of the social connection model: judging background conditions. Young describes how guilt and liability models of responsibility tend to assume morally acceptable or ideal background conditions, where the actionable harm "consists in a morally and often legally unacceptable deviation from this background structure" (Young $2011,107)$. However, as a model of responsibility "derived from an understanding of the mediated connections that agents have to structural injustices" (Young 2011, 107), part of the task of the social connection model is not only to question deviations from an accepted norm but to question the accepted norm itself. Our endorsement of any background condition should be predicated on our investigation and assessment of that condition as not contributing to any kind of systematic harm or structural injustice. To 
uncritically accept institutional rules and norms, and to defend ourselves on the basis of the very fact that we are only operating on accepted institutional rules and norms, is negligent and only reinforces the responsibility we bear for structural injustice. Indeed, this defense is precisely what spurred Arendt's now famous critique on "the banality of evil", arising from the Eichmann trial. Young speaks to how our acceptance of unjust background conditions implicates us in harming others when she argues that while we "should not be blamed or found at fault for the injustice we contribute to... we can and should be criticized for not taking action, not taking enough action, taking ineffective action, or taking action that is counterproductive" (Young 2011, 143-144). On this account, assuming that background conditions are morally acceptable when they are often just the opposite would constitute any one of the enumerated actions for which we deserve criticism.

The third component of the social connection model, forward-looking focus, has already been dealt with tangentially in the discussion of guilt and responsibility above. I emphasized that, based on Young's analysis of Arendt, guilt is backward-looking in that it seeks to hold an individual or individuals responsible for some actionable harm that has come to a terminus. In contrast to where guilt seeks to compensate for the past, the social connection model encourages a more forward-looking focus where "all those who contribute to processes producing unjust outcomes... work to transform those processes" (Young 2011, 109). Young acknowledges that any attribution of responsibility carries plural temporality, and accepts that even the social connection model involves a degree of backward-looking focus. However, whereas the purpose of the backward-looking focus for guilt-based models of responsibility is to praise or blame individuals, the backward- 
looking focus of the social connection model is intended to help us understand "how structural processes produce and reproduce injustice" by developing "an account of how they have come about and operated" (Young 2011, 109). This type of backward-looking focus is more of a historical study that serves as a jumping-off point for taking responsibility, rather than being the locus of that responsibility. As discussed above, taking responsibility in this forward-looking sense reflects a strong commitment to the goals of cosmopolitanism in the acknowledgment and uptake of obligations to others regardless of distance. Forward-looking responsibility is a principle that, when put into practice, affirms the existence of a global moral community.

The fourth and fifth components of the social connection model go hand in hand-it follows from shared responsibility (the fourth component) that collective action (the fifth component) is required. Moreover, these two components follow from the fact that the social connection model is deliberately non-isolating. Young describes shared responsibility as a responsibility that one bears personally, but that is not borne alone. She elaborates, "My responsibility is essentially shared with others because the harms are produced by many of us acting together within accepted institutions and practices, and because it is not possible for any of us to identify just what in our own actions results in which aspects of the injustice that particular individuals suffer" (Young 2011, 110). This necessitates collective action on both a theoretical and a practical level. If responsibility is essentially shared, it is nonsensical to assert that any individual is expected to act on that responsibility alone. Additionally, the task we are responsible for in cases of structural injustice is simply impossible to accomplish absent collective action. The processes in question "can be altered only if many actors from diverse positions within 
the social structures work together to intervene in them to try to produce other outcomes" (Young 2011, 111). It is important to note that these two components of the social connection model in particular are what constitute taking political responsibility following Arendt—with politics in this case, according to Young, meaning "public communicative engagement with others for the sake of organizing our relationships and coordinating our actions most justly" (Young 2011, 112).

In sum, application of the social connection model will simultaneously imbue us with two senses of responsibility and, hence, motivation to action. First, we are encouraged to more widely assign responsibility by recognizing how it is that any given instance of structural injustice has come about. Assigning responsibility involves observing who has contributed to processes that generate injustice, and emphasizing the consequent obligation to take responsibility. Second, having assigned responsibility in this way, we are then encouraged to take responsibility through forward-looking constructive political action to counteract the structural injustice. Importantly, the emphasis on political responsibility qua collective action provides not only the imperative "why" of a solution but also the practical "how". The social connection model thus offers an effective framework for thinking about our relationship to structural injustice on a local and global scale, both in terms of our role in creating it and our obligation to participate in rectifying it. Indeed, this dual focus is the essence of Young's purpose in creating the social connection model and in her initial discussion of Arendt's different categories of responsibility: for too long we have been divorcing ourselves from one or both of our relationships to structural injustice, either causal or remedial, and the only way things will change is if we reconcile ourselves to these relationships and take 
political responsibility. The social connection model brings these relationships and obligations into focus - and in so doing, socializes the praxis of cosmopolitan global citizenship — and aims to transform our mere recognition of relationships into action based thereupon. In this way, the social connection model strongly supports the fundamental justice-focused project of cosmopolitanism as outlined in the previous chapter, and strengthens the ensuing praxis of cosmopolitan global citizenship.

\subsection{Young's Mixed Cosmopolitanism}

I now turn my attention to the task of explaining how, given the goals that each approach describes, the social connection model can be understood as implying a theory of cosmopolitan justice. To begin, though, we must recognize the variety and nature of different streams of cosmopolitan thought. My focus on Held's account of cosmopolitanism in Chapter 1 (pg. 8) is illustrative of the history of cosmopolitanism and of its most primary tenets. Yet while the global community outlook of cosmopolitanism may be relatively consistent across approaches, the basis upon which that outlook rests can differ substantially. This is addressed by Gillian Brock in her article "Contemporary Cosmopolitanism: Some Current Issues”. Brock discusses the differing requirements for cosmopolitan justice, drawing a sharp distinction between humanist and associativist/relational conceptions of cosmopolitanism. She explains that humanist theorists "believe that our duties of justice track our shared humanity. We have duties of justice toward all human beings in virtue of our humanity" (Brock 2013, 691). In contrast, she describes how associativists and relational theorists "believe duties of justice track co-membership in some association, such as political or economic association. Unless we are members of some important association, we have no duties toward 
persons" (Brock 2013, 691). Brock points out that the associativist position has become especially relevant to cosmopolitan thought in recent years, given the rise of globalization and the widely-held contention that all persons are related via a global economic association.

While Brock's distinction between humanist and associativist positions is well taken as a general characterization of streams of cosmopolitan thought, I worry that it is an incomplete analysis. Insofar as Young's social connection model speaks to both humanist and associativist theories of justice, I argue that it can be interpreted as a "mixed" theory of cosmopolitan justice. I appeal to Sen's notion of the imperfect duty to aid to bolster this mixed cosmopolitanism, the recognition of which demonstrates both the cosmopolitan nature of the social connection model and the falsehood of the humanist/associativist dichotomy that Brock implies. The humanist and associativist components of the social connection model together provide a clear picture of the makings of the global moral community, and its prescriptions for dealing with structural injustice constitute a guide to the praxis of cosmopolitan global citizenship.

Given that the social connection model assigns responsibility for structural injustice based on the existence of some causal network of norms, actions, and outcomes-albeit a nexus that is too vast and complex to navigate via traditional models of liability - it makes sense to categorize the social connection model as an associativist or relational approach. Indeed, given Young's work in feminist ethics, it is likely that the social connection model was conceived of and situated in the realm of relational theory more generally. However, the social connection model does not seem so callous as to maintain that absent associations, we have no duties to persons whatsoever-a feature 
that Brock identifies as common to many associativist accounts. In fact, one of the very things the social connection model seems engineered to combat is the idea that having no associations means having no duties to persons. Young's discussion of Arendt is predicated on the notion that believing oneself to be free of associations to some oppressed group is not enough to absolve one of responsibility. Admittedly, the social connection model mostly sets out to prove that this belief is fundamentally flawed. The social connection model is in this way associativist. However, I am not prepared to admit that Young would maintain that an utterly unentangled third party has no obligations whatsoever when faced with situations of injustice (structural or otherwise). In fact, Young reminds us that "No philosopher who restricts the scope of obligations of justice to members of the same nation-state believes that there are no moral obligations that extend beyond borders. Most people are ready to agree that human beings have some moral obligations to other people just because they are human" (Young 2011, 136). This indicates that while the social connection model has elements of an associativist approach, it also honors some humanist elements.

In her insightful investigation of Sen's imperfect duty to aid, Susan Murphy provides an account of what specifically grounds our duties to persons "just because they are human". Through her reading of Sen, Murphy highlights that it is not some vague and fantastical notion of shared humanity that binds us together. Rather, Murphy describes Sen's idea of a "moral duty to assist that is incumbent in all human beings in their capacity as agents simply qua status as moral agents" (Murphy 2014, 370). This helpfully specifies the humanist impulse toward an ambiguous but unifying "something", thereby giving credence to the existence of a shared human quality while identifying that quality 
as something with which we can conceptually and practically engage - thereby socializing our concept of obligations. Indeed, practical engagement is crucial to fulfilling our duty to assist, given that "Sen takes action to be the locus of practical reasoning where agents are required to take responsibility for the outcomes of their actions on all those who are affected by this action" (Murphy 2014, 371). Taking responsibility is thus equated with action, a stipulation that is reflected in the social connection model's basis on political responsibility per Arendt's understanding: that is, we ought to take public stands about actions and events that affect broad masses of people, and as moral agents we ought not to be indifferent to the fate of others. There is therefore a streak of humanism to Sen's imperfect duty to aid, and this humanism is compatible with and emblematic of the aims of the social connection model.

After specifying the source of our imperfect duty to aid, Murphy elaborates on the mechanisms by which we may come to be held responsible for injustice that is ostensibly not connected to us via associativist means as in the social connection model. She explains that even in cases where there are no outcomes of an action for which an agent must take direct responsibility, "An agent can come to be a duty-bearer indirectly. In cases where rights-holders cannot have their rights fulfilled or perhaps have had their rights violated, others with a capacity to act have, according to Sen, a duty to act to assist the agent (as rights-holder)" (Murphy 2014, 372). Thus, the imperfect duty to assist is conceived of as a correlative of rights; even when it is not specified who must meet the requirements of a right, a third-party obligation falls on the shoulders of any reasonable consequence-evaluating agent who is concerned with her general duty to help others when reasonably feasible. This assertion is equally applicable to cases of specific 
wrongdoing and to cases of structural injustice, thereby encompassing both humanist and associativist motivations. If I witness someone's rights being violated—say a defenseless person is being relentlessly beaten- $-\mathrm{I}$ am obligated to intervene because of my status as a moral agent with the capacity to act. Similarly, if I am aware of structural injustice in the form of institutionalized racism (for example), I am obligated to work against this trend insofar as I am able, given that I know about the wrong being done and that I have the capacity to act. To refrain from assisting in either of these cases would bring me into the realm of Arendt's second category of responsibility, wherein people are not guilty of crimes but are responsible in that they have passively supported the guilty through simple lack of intervention.

The vast humanistic scope of an imperfect duty to aid, where we ought not to be indifferent to the fate of others (Arendt, Young) and where we ought to help others where feasible (Sen), may seem daunting and excessively broad. Indeed, worry about the unrealistic demandingness of such a large circle of concern is a common critique of cosmopolitanism and its global moral community cornerstone. But Sen accounts for this in the acknowledgment that it is not possible to act on the interests of everyone all the time. He allows that agents have to pick specific actions to undertake and for whom, meaning that his duty of assistance requires a robust method of practical reasoning (Murphy 2014, 373). This method of practical reasoning takes shape in "situated evaluation", which means that the agent carefully considers the particular position from which they are making their decision. The effect of this is that agents can accommodate special obligations and partiality without shirking responsibilities that are perhaps more distant but no less urgent. To elaborate: 
Sen's account is sensitive to social pluralism and special relationships, but demands that borders and boundaries remain porous when it comes to the task of practical reasoning, determined instead by the reach of activity and the consequences of action. Thus, he rejects as arbitrary the limiting of concern or consideration to a particular group. Further, within this account, acting to assist another may represent the beginning of a relationship rather than the complete fulfilment of a moral obligation. (Murphy 2014, 374)

Despite the humanistic foundation of Sen's imperfect duty to aid, the appeal to "the reach of activity and the consequences of action" shows that associativist considerations also have a place in determining our moral obligations. Sen's tactic of situated evaluation uses associativism to temper the otherwise overwhelming humanist obligation to do right by everybody all the time. In short, Sen's imperfect duty to aid sees that the demands on an agent should involve overarching concern for all moral agents, while being narrowed by the particular linkages in which an agent participates. This demonstrates the symbiosis of humanist and associativist theories of cosmopolitan justice in specifying our duties to persons.

I also want to pay particular attention to Murphy's language of "the beginning of a relationship" because of the forward-looking focus it expresses. Recall that in Arendt's discussion of guilt and responsibility, backward-looking focus was identified with assignment of guilt or blame while forward-looking focus was identified with taking responsibility. Backward-looking blaming and punishing functions as the terminal fulfillment of some obligation, which is inappropriate to ongoing issues of structural injustice. In light of this, the social connection model seeks to reshape our understanding of justice and emphasize that it is a process in which we must continually engage. Sen's imperfect duty to aid thus complements the social connection model in that it establishes 
the duty to aid as a forward-looking taking of responsibility, where the act of assisting is not the terminus of a finite duty but the beginning of an ongoing one.

I have thus far focused on demonstrating that humanist and associativist cosmopolitanism may not always be mutually exclusive and dichotomous, and in fact they work in tandem to create comprehensive socialized accounts of responsibility in both the social connection model and Sen's imperfect duty to aid. This indicates that the social connection model can be interpreted as being based on a "mixed" cosmopolitan theory of justice. I now want to identify the ways in which the social connection model is cosmopolitan not just in its conception of justice, but in the attitude and activity it encourages and necessitates. I argue that the social connection model embodies a conception of cosmopolitanism as praxis - which, combined with an understanding of citizenship as praxis, I take to be constitutive of cosmopolitan global citizenship. Given the social connection model's emphasis on collective responsibility remedied through collective action, and the potential for collective action and advocacy offered by the group setting of international service learning projects, in the next chapter I will apply the social connection model to these types of development projects. In so doing, I hope to show that the social connection model can serve as a practical blueprint for how to do global citizenship — because ultimately global citizenship is not a demonstrable status, but is instead a sustained praxis of cosmopolitanism.

To build the idea of cosmopolitanism-as-praxis, I return to the idea of the "global moral community" that I have been using, borrowed from Nigel Dower. Dower holds that understanding one's responsibilities as a member of the global moral community will help convert principle into action, and a necessary precondition is that "attention needs to 
be given to the creation of the right conditions of identity, motivation and a sense of being rooted in relevant communities of concern, which of course need not be located in one specific geographical area" (Dower 2002, 33). The social connection model makes steps toward the conditions of identity that Dower advocates by rooting us in relevant communities of concern, which are necessarily global. Our collective participation in structural processes that are "global in scope and condition the lives of many people within diverse nation-state jurisdictions" highlight that our community of concern extends far beyond the local and otherwise immediate (Young 2011, 125). Dower, Sen, and Young's ideas all express the conviction that the political-geographic boundaries of nation-states do not exclusively define our obligations as long as our actions have an impact across those boundaries. The moral community is therefore necessarily global in both a normative and a descriptive sense; from Sen we know that we ought to be concerned with injustice and suffering regardless of its distance from us, and from Young we know that our responsibility for justice "is not [emphasis mine] restricted to those close by or to those in the same nation-state as oneself, if one participated in social structural processes that connect one to others far away and outside those jurisdictions" (Young 2011, 142). Recognition of these responsibilities, Dower would argue, grounds one's identity as a member of the global moral community and in turn motivates us to act against structural injustice on a global scale. Dower's emphasis on the proper "conditions of identity" as precursors to action thus link a cosmopolitan orientation to the world with the eventuality of actions arising therefrom-cosmopolitanism-as-praxis.

It should be noted that when it comes to conditions of identity, cosmopolitanism does not necessarily demand that one identify as a citizen of the world to the exclusion of 
all else. Rather, it is possible to practice cosmopolitan global citizenship while choosing to take responsibility over particular structural processes in which one sees oneself reflected. For example, global movements that appeal to identity and the particular aspects of persons include feminism, fair-trade advocacy, solidarity with low-wage workers, support for refugees, and many others. These global movements benefit from the voices and activism of people whose lives have been uniquely affected by these particular structural processes. Aligning oneself with one such identity or global movement is perfectly acceptable and does not preclude global citizenship and a cosmopolitan ethic addressing injustice in its myriad forms. On reconciling partiality with cosmopolitan obligations, Nussbaum argues "we need not give up our special affections and identifications, whether ethnic or gender-based or religious... But we should work to make all human beings part of our community of dialogue and concern, base our political deliberations on that interlocking commonality, and give the circle that defines our humanity a special attention and respect” (Nussbaum 1994). So, as long as one's identity and chosen activism are informed by global perspectives and working toward the end of a more integrated global community, the praxis of cosmopolitan global citizenship and partiality can coexist. In fact, I would argue that activism guided by partiality and identity is a way to take responsibility in accordance with cosmopolitan global citizenship, without that responsibility being overwhelming and unrealistically broad. A global community of people collaborating on specific issues with global and intersectional perspectives is a strong concept of cosmopolitan global citizenship in practice.

Tully's notion of diverse citizenship, discussed in section 1.1, aligns closely with the kind of praxis suggested in Dower's work and allows us to build a cosmopolitan 
action-based understanding of global citizenship. Congruent with Dower's emphasis on turning principle into action, Tully argues that action is not merely incidental to citizenship —instead, citizenship consists entirely in action. Rather than seeing citizenship as a status bestowed and guaranteed by institutions, Tully argues that "Agents (individual or collective) become civic citizens only in virtue of actual participation in civic activities" (Tully 2014, 37). The primacy of action in this case comes from the idea of "citizenship as negotiated practices, as praxis - as actors and activities in contexts" (Tully 2014, 35). For Tully, one cannot be a citizen without the all-important doing of citizenship. It is worth noting that citizenship-as-praxis, "actors and activities in contexts", is highly compatible with the kind of practical reasoning via situated evaluation for which Sen advocates. The "actors and activities in contexts" nature of citizenship is also enshrined in the components of Young's social connection model: judging background conditions, recognizing collective responsibility, and taking collective action all inherently involve actors (as opposed to mere potential agents) and recognition of their particular relational contexts and responsibilities.

It therefore emerges that the social connection model is a uniquely beneficial tool for cosmopolitan global citizenship in that it provides a framework for citizens to discern what they ought to be doing, based on their relationships and the obligations that arise therefrom. The imperative of actively taking responsibility that undergirds the social connection model expresses the framework's congruence with and facilitation of Tully's citizenship-as-praxis. Given the cosmopolitan theory of justice underlying Young's Arendtian analysis and leanings, we may also interpret the social connection model as gesturing toward a concept of cosmopolitanism-as-praxis. Cosmopolitanism-as-praxis 
and citizenship-as-praxis amalgamated in the social connection model comprise a definitive way to approach doing global citizenship: it is a praxis of citizenship motivated by a cosmopolitan identity and worldview. Moreover, the capabilities-based humanization of cosmopolitanism undertaken in the previous chapter and the socialization provided by the social connection model means that a praxis of cosmopolitan global citizenship resulting from the use of the social connection model will be appropriately inclusive and relational, rooted in existing and ongoing obligations to others across boundaries. The social connection model can be used to guide citizens' reflection on their relationships and obligations, while at the same time serving as a mechanism to turn reflection on obligations into action based thereupon.

So, to summarize: humanist cosmopolitanism tracks our shared humanity, and associativist cosmopolitanism tracks our co-membership in some association. The social connection model sees us as united in our "humanity" qua moral agency, and thereby as co-members in a global moral community. In addition to this mixed humanistassociativist linkage, the social connection model demands that we not ignore the more concrete socio-political linkages of which we are a part, and which produce situations of structural injustice. Our causal connection to these situations of injustice combined with our agency and capacity to act constitute undeniable membership in a global community, united both by morality and circumstance. The social connection model can be read as providing a framework for uncovering the obligations and activities of a humanized and socialized praxis of cosmopolitan citizenship. In the next chapter I examine the ways in which international service learning projects approach global citizenship, and show how these projects can be enriched by applying the social connection model. 


\section{Chapter 3: Cosmopolitan Global Citizenship and International Service Learning}

Given that international service learning projects often appeal to the notion of global citizenship, in this chapter I conduct an investigation of how the motivations to participate in international service learning projects either reflect or contradict the goals of cosmopolitan global citizenship as outlined in this thesis. The results of this investigation may have bearing on our assessment of international service learning projects - namely, whether they are or can be effective catalysts to Dower's "conditions of identity" and whether they truly express the principles and praxis of cosmopolitan global citizenship. I have divided this discussion into three sections. In the first section, I define international service learning projects and establish that their activities are often situated with reference to the project of global citizenship. In the second section I examine how international service learning projects construct global citizenship itself, specifically whether their concept of global citizenship seems to involve an appeal to or understanding of cosmopolitan obligations and responsibility. I frame this discussion with respect to the way international service learning — and international development more generally — is marketed to citizens, using testimonial evidence to illustrate participants' perceptions of their own impact through service. In the final section I demonstrate how the social connection model, in its capacity as a tool to uncover the obligations and activities of global citizenship, can enrich the learning and development outcomes of international service learning projects. The overall argument of this chapter suggests that international service learning projects, under the right conditions, have the potential to be both instances of and a means to a more widespread praxis and culture of cosmopolitan global citizenship. 


\subsection{Appeals to Global Citizenship}

Rebecca Tiessen and Robert Huish explain that international experiential learning provides an opportunity for students to apply their skills in the real world, while developing an increased understanding of inequality, poverty, and global justice. "International experiential learning" is an umbrella term referring to a variety of travelbased educational programs including internships, field courses, and study abroad. Tiessen and Huish note that "In spite of the growing popularity of the term global citizenship, it remains a largely elusive concept with many definitions", but at the very least it is clear that "the desire for global citizenship identity is closely linked to the growth in international experiential learning" (Tiessen and Huish 2013, 7). To reiterate, global citizenship and the desire for learning experiences abroad appear to be intimately connected. To support this observation, in what follows I provide examples of varied international experiential learning opportunities — with a particular focus on international service learning projects (ISLPs) — making reference to global citizenship as a component or outcome of the experience. I refer to these materials not as sources of substantive proof, but as illustrative examples of the linkage between ISLPs and global citizenship as argued by Tiessen and Huish in their book Globetrotting or Global Citizenship?

In ISLPs and volunteer tourism, participants engage in a community service activity intended to benefit their own learning while also benefitting the community. Through their emphasis on civic engagement and concern with global justice, ISLPs should have the potential be an excellent tool to promote global citizenship. Global Vision International, or GVI, is a self-described "multi-award winning social enterprise that runs high impact volunteer and international education programs" (GVI World 
2012). In an explanatory blog post from their website, international service learning is defined as a "structured academic experience" with three main characteristics:

1) It provides you with the opportunity to engage with an organized service activity that addresses community needs

2) It offers you practical experiences, interactions, and cross-cultural dialogues

3) It incorporates reflection of the experience in order to gain a broader appreciation of the host country, of academic study, and of global and intercultural issues, to ultimately become a more global citizen. (Clark 2017)

GVI thus connects ISLPs with the outcome of global citizenship informed by the experience of cross-cultural immersion, service, and broadened perspective and awareness. This approach to fostering global citizenship is mirrored in other international service learning projects - for example, those run by post-secondary institutions. The University of Oregon offers an ISLP through the Holden Center for Leadership and Community Engagement. During their Alternative Break, Oregon students have the opportunity to travel and participate in a service activity in lieu of a more traditional leisure-focused spring break trip. The website explains:

Participating in an Alternative Break is your chance to make a difference in a part of the country or world you have never been. You'll learn about different cultures and perspectives... The trips focus on a common purpose and foster collaboration and social change... During the trip, you will participate in daily reflections, leadership lessons, evening debriefs, and topical discussions; a curriculum that promotes self-awareness, global citizenship, and leadership. (Holden Center 2017)

Once again, the ISLP's components of cross-cultural experience, social justice, and broadening of perspective are seen as precursors to global citizenship. Yet note that beyond an implicit and vague association of global citizenship with the international 
experience and active reflection thereupon, "global citizenship" itself remains an illdefined buzzword for both Oregon and GVI.

AIESEC, a youth leadership organization with a global focus, also makes use of the buzzword in their Global Citizen social internship program. On the AIESEC website, it is explained that the program matches youth with "Internship adventures that will help you develop life-long friendships and provide experiences to shape you for years to come. Together we'll change the way you see and understand the world" (AIESEC 2016). However, further reading about the Global Citizen program reveals more about how AIESEC conceives of global citizenship, unwittingly situating it as part of an asymmetrical global power dynamic. They stipulate that "AIESEC is present in 126 countries and territories though we focus on creating social internship opportunities in developing and less economically developed countries/territories. Because of this, there are almost no Global Citizen projects available in regions such as western Europe" (AIESEC 2016). AIESEC thus implicitly constructs global citizenship as a unidirectional way of relating across borders: global citizenship is a way for people in and from the affluent Global North to engage with the poor Global South. AIESEC's particular brand of global citizenship — again, vague but with troubling implications - thus may contribute to the global inequality that their internship opportunities presumably seek to remedy. A global citizenship like AIESEC's that has built into it a static global power or economic hierarchy does not express the cosmopolitan notion of a unified global community. In fact, it expresses just the opposite: a world community made up of haves and have-nots, with restrictive and skewed relationships between the two. 
In a different vein of international experiential learning, Xperitas trips attempt to develop global citizenship not only through service and structured work activities but also through simple immersion in different cultural environments. Offering both language programs and community partnership programs, the organization describes its mission as follows:

Xperitas is a nonprofit educational organization dedicated to promoting global citizenship through authentic immersion experiences. Born from the decades of shared experience of Intercultural Student Experiences and Global Citizens Network, Xperitas offers programs that embody true language and cultural immersion, inspire personal connections with diverse individuals and communities worldwide and provide transformational experiences for our participants. (Xperitas 2017)

The community partnership programs in particular offer the opportunity for collaboration with "indigenous and marginalized communities around the world" in community-led projects, the service and language immersion components of which work together to become "a vehicle to greater cultural understanding, cross-cultural friendships and ultimately towards increased global cooperation" (Xperitas 2017). Yet once again we see appeals to cross-cultural understanding and cooperation as somehow related or foundational to global citizenship, without any substantive explication of global citizenship itself.

Global Citizen Travel breaks with this trend, providing a simple yet thorough account of global citizenship and its utility. The mission statement includes the following:

Students want to become what we call, 'global citizens.' Simply put, global citizens look to take into consideration the world as a whole above the immediate world that they live in. The more globally-minded citizens we have, the better the world can come together and put global issues above those of an individual 
nation. Students that travel abroad identify with this and look for travel experiences that allow them to connect with a global community that reciprocally cares about the social responsibilities that we all share. (Global Citizen Travel 2012)

However, in a perverse and frustrating contradiction, this promising account and understanding of global citizenship is accompanied by an explanation of the apparent values of Global Citizen Travel clients - which in no way reflect social responsibility, reciprocity, or the sense of belonging in a global community. When it comes to travel, the company asserts, “Anyone can take a picture in front of a globally recognized place or structure. Students want to sleep by it, skydive over it, climb it and do anything else they can think of that is adventurous and unique" (Global Citizen Travel 2012). Moreover, Global Citizen Travel trips are planned around the fact that students love to party: "Nightlife is as much a part of the culture as museums or the local cuisine to most students... Local beer, local dance, think globally, act locally" (Global Citizen Travel 2012). Global Citizen Travel's focus on adventure tourism and "global citizens that share the travel bug" is utterly devoid of anything resembling even their own definition of global citizenship, thus revealing their appeal to global citizenship as little more than a marketing strategy.

Another recurring theme in international experiential learning alongside global citizenship seems to be a search for "authenticity". Global Citizen Travel states that their clients prefer "interacting with locals in authentic settings... [as] travelers not tourists" (Global Citizen Travel 2012), and Xperitas makes reference to their provision of "authentic immersion experiences" (Xperitas 2017). Explorica, another international service learning organizer, "is dedicated to the idea that educational travel is much more 
than sightseeing; we connect you with people, places and cultures through authentic activities you won't find anywhere else". This quest for authenticity implies that there is both a "real" or "authentic" Global South, and a "fake" Global South sold to the Global North. ISLP organizations' and participants' understanding of themselves as "travelers" rather than tourists, as being engaged in service to others rather than selfish enjoyment, reveals an expectation and entitlement to be included in the "real" Global South. Such an expectation, even just implicit in the discourse of authenticity, indicates that ISLP participants are coopting the space of the Global South as their own not just in "the use of communities in... the Global South as extensions of classroom spaces" (Tiessen and Huish 2013, 3), but also in their sense of entitlement to "authentic" space which exists for and by locals. It is as if, through their involvement with an international experiential learning program, participants see themselves as having transcended the artifice of tourism and are thus worthy of and entitled to the "real" Global South experience and community. One student recalls, "During my own ISL placement I struggled with the concept of authenticity on many occasions, and played into similar romanticized narratives that exotified the culture of my placement country" (Difruscio and Rennick 2013, 75). While a more in-depth discussion of authenticity and travel is beyond the scope of this project, my intention in raising the issue is to highlight that in a way similar to the divisive and hierarchical worldview implicit in some concepts of global citizenship (i.e. AIESEC), the notion of an "authentic" Global South constructs culture in the host community as monolithic and distinctly "other". This othering is antithetical to the cosmopolitan notion of a global community, and so discussions of and claims about authenticity must be carefully analyzed. 
To summarize, the ISLP materials examined in this section demonstrate frequent appeals to global citizenship as a goal of participation in service activity abroad. However, global citizenship itself is rarely defined and is more commonly only vaguely related to concepts of cross-cultural relationships, social change, and transformational personal experience. Without a substantive definition and understanding of global citizenship — in other words, without a "why" undergirding the "what" of global citizenship-ISLPs and other forms of international experiential learning run the risk of being structured and marketed primarily on the values of adventure-seeking and employment marketability. I examine these motivations and their role in ISLP participants' self-perception more deeply in the next section.

\subsection{Marketing Development}

Having illustrated the prevalence of appeals to global citizenship in international travel and service learning experiences, I now examine the nature of those appeals to global citizenship. What ISLPs mean by "global citizenship", and the way that international development and social justice are marketed to potential ISLP participants, can have an effect on the reasons participants seek out international opportunities. Marketing development is not just a project of particular institutions running ISLPs but a project of society as a whole. Governments, charity organizations, development agencies, national myths/identity, and other social and political institutions all have an effect on the way people in the Global North orient themselves toward the Global South — which is the site of many of the ISLPs and development projects that students increasingly flock to. Motivations to engage in development work and in ISLPs can be either self-regarding or other-regarding, depending on the way that development is marketed and the consequent 
way that citizens of the Global North see themselves relative to the Global South. Each orientation is rife with problems, and in what follows I will evaluate specific examples of the ways people are encouraged to conceive of their own involvement with ISLPs. In particular, I contend that other-regarding motivations (specifically those to do with cosmopolitan obligations and responsibility) are at the core of a good praxis of cosmopolitan global citizenship, but that they are underrepresented in international service learning. This may have a negative effect on the citizenship education of project participants, and on the development outcomes of the service project itself.

Elaborating on the extension of classroom/learning space that is inherent to ISLPs, Tiessen raises important concerns about the effect of sending students across borders for the end of a globalized education. She warns, "While we have much to learn from people and organizations committed to social and/or global justice, we must also be careful not to treat communities in the Global South as laboratories for testing an academic or career choice" (Tiessen and Huish 2013, 3). This statement implicitly identifies two motivations for participating in ISLPs: an interest in and commitment to global justice, and the opportunity to engage in hands-on application of particular academic or work skills. I take the former to be expressive of an other-regarding motivation, and the latter to be expressive of a self-regarding motivation. To elaborate, I conceive of self-regarding motivations as having to do with personal gains and benefit, whereas other-regarding motivations are based on fulfilling a perceived or actual obligation to others.

While these two positions or motivations are not necessarily mutually exclusive, Tiessen's cautionary tone stems from her research that demonstrates the relative 
unimportance of aid and of global justice and equality to students' decisions to partake in ISLPs. John D. Cameron, referencing the results of a sustained project of interviews and analysis conducted by Tiessen, offers the following insight:

... Students' primary motives for volunteering in developing countries related to career development and to personal learning and growth... Not only was 'a desire to help others' far down on the list of students' primary motivations, but concerns about 'social justice or solidarity' were not identified by any of the sixty-eight participants in her study as a motivation for participation in international development volunteer programs. (Cameron 2013, 23)

This data indicates a predominantly self-regarding attitude on the part of ISLP participants, troubling in that they seem not to prioritize the wellbeing and circumstances of those who they are allegedly serving. "Service" implies an other-regarding motivation, when in reality participants' engagement with the wellbeing and circumstances of communities abroad seems merely incidental to their larger academic and career goals. Illustrative of this trend, and in particular of the way that institutions manufacture it, is a statement from the Western University 2014 Strategic Plan, titled "Achieving Excellence on the World Stage". ${ }^{3}$ The plan declares that "Today's students seek to round out their degrees by applying their acquired knowledge and skills in hands-on, real-world settings. Students and employers alike expect to do this through such learning activities as... study-abroad and academic exchange programs; and social justice or international development initiatives with non-governmental agencies" (Western University 2014, 12). Following this statement, the plan pledges that Western will invest accordingly so that

\footnotetext{
${ }^{3}$ My reference to Western University — which, in the interest of full disclosure, is my alma mater-is not meant as a condemnation of this particular institution. Rather, given my familiarity with the institution and my participation in its Alternative Spring Break program, I am using its literature as a flashpoint for critical analysis of approaches to global citizenship and ISLPs. Western University is not the sole institution under investigation, but rather an illustrative example of trends in service learning that occur across many institutions, postsecondary and otherwise.
} 
any academically eligible student will have the opportunity to participate in international experiential learning.

The message that this sends is significant because not only does it present students with the opportunity to engage in development work abroad — which is not itself a bad thing - but it constructs that experience and the global citizen identity attained through that experience as almost necessary for eventual academic and career success. Note the phrasing that students and employers alike "expect" engagement in these kinds of hands-on projects. Though these service learning experiences can be conducted domestically (and Western does offer them), the language of expectation as applied to international experiential learning expresses both a sense of entitlement to the Global South's space and time bordering on neocolonialism, and the troublesome perception of social justice work abroad as just a means to an end. As Barbara Heron points out, "we take for granted that we can go to, live in, and be active in other people's countries - and lives - if we choose to do development work" (Heron 2007, 45). The end of the development work, in this particular case, is ostensibly that the participant will have obtained demonstrable "global citizen" status through their involvement with an ISLP. This goal demonstrates a self-regarding motivation for development work, focused not on issues of justice and well-being but on marketing oneself to employers post-graduation. In fact, this motivation is not anomalous: Global Vision International markets their program with the argument that "Overall, international service-learning is a great way for you to gain global competency and leadership skills, and has become a focus for many higher education institutions. By gaining international knowledge and experience, you will become more competitive in both the domestic and the global marketplace" (Clark 
2017). The content of Western's strategic plan and this illustrative example from GVI demonstrate that institutions have the power, potential, and even a vested interest in encouraging a particular view of development work in the way that they market their programs. Tiessen's concern about treating the Global South as a laboratory for testing an academic or career choice therefore seems well-founded.

To summarize the trend of self-regarding motivations for development, I turn again to Cameron. He explains, "the motivations for the promotion of global citizenship programs and international experiential learning courses from the perspective of senior university administrators appear to be related primarily to the marketing goals of positioning their universities as key players in the training of a globally-competitive workforce" (Cameron 2013, 23). This is a dangerous attitude around which to build development projects, risking disregard of the ends and development goals of the Global South community in favour of providing ISLP participants with whatever it is they (or their associated institution) need. However, it is important to note that the reservations I and others express about the self-serving nature of this kind of development work does not necessarily mean that an uncritical move toward other-regarding motivations is the answer. A particular sort of other-regarding motivation-a motivation of benevolence rather than solidarity — runs a great risk of being inappropriately invasive and counterproductive to development goals, as do self-regarding motivations. This is due in part to larger societal conceptions of Global North/Global South relations and accepted global power dynamics.

Heron provides some insight on the inaccuracies and dangers of this perceived global hierarchy, where the affluent nations of the Global North are positioned as the 
hope and salvation of the poor Global South. She describes the narrative adopted by the Global North as "a story where 'developing countries' appear to be in a state of unmanageable disarray, and where what seems to matter is not just the assistance that is given, but the helping imperative and the effect that 'helping' the passive Other will have on our own life experiences" (Heron 2007, 5). What I want to focus on here is how the Global South is portrayed as helpless and without agency, a passive recipient of aid from the resource- and knowledge-rich Global North. This view of the world generates an obligation for the Global North to provide assistance to the Global South in the form of financial aid, provision of resources, or volunteering as in the case of ISLPs. Speaking particularly about the British context, April Biccum explains "The aim of this marketing campaign is to sell to its citizens the idea of poverty eradication as a moral imperative of the British nation. It is the possession of this moral duty which in part defines the UK as 'developed' and purports to write this identity into the national consciousness" (Biccum 2010, 50). Heron dubs this phenomenon the "helping imperative," and connects it to approaches to development that actually disempower and further subjugate the already struggling communities of the Global South. She elaborates, "We inadvertently paint ourselves larger-than-life, or at least larger than our lives in Canada, when we perceive the Southern context as needing and amenable to our interventions" (Heron 2007, 43). And indeed, this is what the helping imperative does: portray the Global South as in need and perpetually open to "assistive" efforts, and the North as justified and magnanimous in imposing its varied programs of development.

While the helping imperative is in part generated by society at large in its concept of global power dynamics, the helping imperative can also be perpetuated by particular 
institutions' marketing of ISLPs. For example, despite the backdrop of self-regarding motivations both in terms of institutional reputation and individual students' academic/career success, Western's Alternative Spring Break program demonstrates how the helping imperative and other-regarding motivations more generally can border on condescension. The online ASB information page describes how Western has "partnered with a variety of community partners and organizations, locally, nationally and globally, who are anxious to benefit from the knowledge, passion, and hard work of students just like you". This short statement contains assumptions that speak to the plethora of problems with other-regarding marketing of development. For instance, the description of community partners as "anxious" to benefit from student contributions implies a certain desperation and lack of agency in generating benefits for one's own community. Moreover, emphasis on "the knowledge, passion, and hard work of students just like you" encourages ISLP participants to see themselves as providing some crucial service to a community with a dearth of these qualities. This is particularly interesting in that otherregarding motivation to provide for a community in need so easily turns into selfregarding motivation where students feel good about themselves for contributing. In the ISLP context, this outcome is perhaps the kind of thing that Heron refers to in her earlier statement about the effect that "helping" the passive Other will have on our own life experiences.

Perhaps part of the reason that the line between self-regarding and other-regarding is so blurry in this case has to do with the nature of the obligation upon which the otherregarding motivation is based. As discussed above, the helping imperative contains within it an implicit reference to the asymmetry between the Global North and Global 
South. I therefore propose that we can situate the other-regarding obligations of the helping imperative within the realm of the distributive paradigm. Recall Iris Marion Young's explanation that the distributive paradigm "defines social justice as the morally proper distribution of social benefits and burdens among society's members. Paramount among these are wealth, income, and other material resources" but also included are "nonmaterial social goods such as rights, opportunity, power, and self-respect" (Young 1990, 16). In short, "what marks the distributive paradigm is a tendency to conceive social justice and distribution as coexistive concepts (Young 1990,16). The distributive paradigm thus constructs an understanding of "helping" in which the helper is generally understood as having more — either materially or socially — than those being helped, and the helper gives to those who are helpless on their own. The other-regarding obligation of the helping imperative thus has a fundamental power imbalance built into it, focused on the obligation to right distributive wrongs and resulting in beneficent but easily corruptible assistive efforts in international development. Through helping, having corrected a distributive injustice and ostensibly reached a relational terminus with the fulfillment of this obligation, the ISLP participant's regard for others can then evolve into a self-congratulatory focus.

However, an other-regarding obligation rooted not in the helping imperative but in a cosmopolitan worldview may yield different results. Here, too, the other-regarding motivation is related to the self in that injustice anywhere is, for the cosmopolitan global citizen, injustice everywhere and thus relevant to one's own community and circle of concern. Yet unlike the distributive paradigm, the obligation being acted on in a cosmopolitan other-regarding focus does not have built into it a concept of haves and 
have-nots. For in any case of material or social injustice, the cosmopolitan global citizen sees that we are all—as members of a single global moral community—-the have-nots, lacking justice. Thus the other-regarding motivation is not a beneficent helping from the have to the have-nots, but a collaborative project of solidarity geared toward a common goal. And crucially, the cosmopolitan obligation is never terminally fulfilled in the way that the distributive obligation is. This keeps the ISLP participant's focus on the global community as a whole, rather than on the experience that helping will have on their own life. We therefore see how the motivations and obligations underlying service work can result in drastically different learning and development outcomes in the ISLP experience.

Post-trip reflections reveal what benefit participants feel they have gained from their ISLP experience, as well as their perception of their impact abroad. I therefore examine these testimonials hoping to identify the kinds of obligations the participants see themselves as fulfilling, and the role they see themselves as having played and are continuing to play in development and global justice. Take the following post-trip testimonial from an Alternative Spring Break participant, describing the value they see in the program: "ASB has something for everyone: the chance to do some good and to make a difference, the chance to travel to a new and different place, the chance to learn new skills and grow as a person, and the chance to meet new people and make new friends" (2014). For this participant, the appeal of the program seems to lie primarily in the personal takeaways related to social and vocational benefits. This is unsurprising given the way ISLPs are constructed as part of a well-rounded university education. The participant also mentions the opportunity to "do some good" and "make a difference," but in light of Heron's explication of the helping imperative and its connection to distributive 
obligations we have reason to be wary of do-gooding. ${ }^{4}$ The only global focus this participant seems to have in the ISLP experience is the simple desire to see another country.

This is the concern that Tiessen points to in the title of her book with Robert Huish: "globetrotting or global citizenship?" What kind of people, with what sort of focus, do ISLPs really attract and produce? In her research interviews with ISLP participants, Tiessen observed that participants recognized that "much of what they learned abroad could be learned in Canada and this raises questions about the value of international service learning... the kind of experience Canadian youth crave is one that offers potential for adventure and travel, while also improving their employability" (Tiessen 2013, 86). This speaks to a globetrotting mindset where given the choice between two equal learning opportunities_ — one abroad and one domestic — students would rather go abroad not out of motivations of service but out of a desire for novelty and excitement. Craig and Mark Kielburger, creators of the immensely popular ME to WE volunteer trips, seem to have picked up on the globetrotting trend and sought to capitalize on it in their rights-based development work. They rationalize that "Canadians want to travel, and they will. So we say, instead of tanning on a beach, give them the opportunity to experience something that, if done well, will lead to a lifetime of contributions beyond a one-time donation" (Kielburger and Kielburger 2013, xi). The ME to WE focus on turning travel into a lifetime of contributions is an attempt to turn globetrotters into global citizens-how successfully they do this is a question best

\footnotetext{
${ }^{4}$ My critique of other-regarding motivations for development and my reference to the helping imperative are not related to a discussion on the nature or possibility of altruism. I am concerned with other-regarding motivations not because of questions about the potential for selflessness, but because of the worries about whether one's estimation of their "helping" can obscure ways in which they are harming.
} 
answered with a thorough case study beyond the scope of this project. I will, however, remark that given the Kielburgers' explicit reliance on a desire and particularly an ability to travel, their ME to WE model of global citizenship seems like it may be accessible only to those who have the resources to effectively fundraise or self-finance. If this is so, we would do well to question whether this is a model of global citizenship that we can accept.

What the "globetrotting" testimonial and attitude to development say about global citizenship is interesting and fraught. I take the particular participant quoted above to be exactly the kind of person the Kielburgers market their volunteer trips to-someone who wants to travel, and is open to parlaying that privilege into both a personal gain and a beneficent effort at international development and poverty eradication. But that kind of initial motivation, absent any sustained interest in global justice/equality and expressing an almost flippant "why not" attitude, can lead to ISLPs that are nothing more than fleeting and self-indulgent tours through the Global South. One ISLP participant recalls struggling with this standard upon arrival:

As soon as we got there, what [the local contact] had really wanted to say was pretty much about how we benefit from their poverty. He just went on about how we just come here and we just leave and that's it and don't hear from them again. So we talked about it, and we tried to challenge that stereotype. It was really, really difficult to hear that... You are going there invading... their homes and doing work there. (Matthews 2013, 106)

This reflection reveals increased awareness of the impact of an ISLP beyond benefit to the participant, crucially rooted in testimony from a member of the local community. ${ }^{5}$

\footnotetext{
${ }^{5}$ By way of a disclaimer/explanatory note, I acknowledge the general absence of the voices of the Global South in my project - partially due to lack of source material, and partially due to my reluctance to critique ISLPs from a situated perspective in which I cannot partake. It is not for me to respond to ISLPs on the
} 
The participant's sphere of awareness and concern has expanded from just the self to include others' experiences — not only the experience of poverty, but the experience of being subjected to development via ISLPs. Yet despite the increased awareness and critical thinking this participant displays, the qualification of the local contact's perception of ISLPs as a "stereotype" is troubling. It implies that the assertion is oversimplified and incorrect, something that must be proven wrong by the participant and the ISLP group's actions. This phrasing, and the ensuing commitment to "challenge that stereotype," express the participant's belief that there is still something fundamentally good about the ISLP's presence that warrants a promise to soldier on and be better, rather than to cease and desist. Assumptions like these are the subject of my concern when projects are pitched as "service learning", obscuring the possibility that the service is done for the participants themselves while in effect working against the interests of the community.

The last testimonial I will consider demonstrates a degree of critical thinking that goes far beyond the "be the change" mentality of ISLPs, expressing an other-regarding motivation beyond the helping imperative and more in line with the broader outlook of a cosmopolitan global citizen. A participant from Western University's Alternative Spring Break program offered this assessment of their time abroad:

In reality, there is only so much you can do for a community in one week's time. I did not go into Costa Rica thinking it would change my life. Nor did I expect to change someone else's. My goal was to make sure that what I worked for in the future, in health care and in life, would be well-informed by multidimensional learning and global perspectives. And that is exactly what the ASB program did

behalf of host communities and partner organizations in the Global South; my critiques are rooted in my own experience as a student in and from the Global North, and I aim to be open and sensitive to modifications from a Global South perspective while refraining from generating that perspective myself. 
for me. I am so grateful for the opportunity to immerse in a new culture, and to have my preconceptions both challenged and validated. (2014)

What is most notable in this perspective is the participant's modest estimation of their own ability to have an impact, and the emphasis on learning not just in a community abroad but learning from that community. Contrary to the inspirational and selfaggrandizing "be the change", larger-than-life assumptions of the helping imperative, the participant explicitly acknowledges that a one-week visit to Costa Rica is not really going to amount to much "change" for anyone involved. The participant does express the hope that the ISLP will have an impact on their future career, but in a way quite unlike the instrumentalism of the self-regarding marketing of global citizenship. Rather, the participant seems to take a knowledge-sharing attitude and aims to carry the global perspectives of their ISLP experience into a praxis—one that sounds like cosmopolitan global citizenship — over the course of their life and career in health care. The obligation being acted upon in this case therefore seems not to be informed by the distributive paradigm, but by the solidarity impulse of the cosmopolitan obligation and worldview. This suggests a commitment to global citizenship not simply in the capacity of having been abroad to enrich the value of one's credentials, but in the sense of integrating international experience and a plurality of perspectives into one's worldview and selfconcept. The indication of the participant's ongoing relationship with diverse perspectives and global issues seems like it may qualify for the "conditions of identity" Dower argues are crucial to the development of a culture and practice of global citizenship. 
The attitude and aspirations espoused by this participant reflect an observation made by a student in a focus group on ISLPs: that "global citizenship is 'a very loaded concept; something that you just can't do in three months'", let alone on a one- or twoweek volunteer trip during a mid-semester break (Matthews 2013, 100). This highlights the grave flaw in constructing ISLPs as a sort of achievement of global citizenship. Being a global citizen is not the terminus of a task, but rather the nascence of an ongoing and ever-evolving relationship with the world beyond oneself and one's own immediate community. The vast inconsistency in participants' perceptions of their impact through ISLPs and their obligations once returning home shows that ISLPs operate with a shallow and ineffective concept of global citizenship. Such a poorly developed sense of global citizenship focused not on processes and institutions but on distribution itself can actually work against a sustainable solution to injustice on a global scale, which ISLPs purport to remedy.

Data from a study conducted by Matthew Mayhew and Mark Engberg reinforces the predominance of the helping imperative in service learning, whether as a motivation or an outcome. Mayhew and Engberg compared first-year success courses that incorporated a service learning component with courses that did not, and found negligible progress in students' social justice focus. They assert, "Embedded in the call for democratic citizenship is an equally powerful charge to colleges and universities for creating curricular and cocurricular programs intended to spur its development... Results from this study suggest that infusing service-learning curricula into first-year success courses can help students make at least some of these important gains." (Mayhew and Engberg 2007, 32). In particular, Mayhew and Engberg found that “Although successful 
in helping students develop their sense of charity, the courses were not as helpful in guiding students toward an increased understanding of their own power and privilege and how to use such knowledge for the betterment of society" (Mayhew and Engberg 2007, 34). That is, the study showed that students who engaged in service learning as part of the curriculum of their first-year success course reported significantly higher levels of charitable responsibility than those who did not. However, levels of social justice responsibility and awareness were not similarly improved. Mayhew and Engberg discuss that there remains debate as to whether the purpose of service learning should be to move students from a charity mindset to a social justice mindset, or whether service learning should challenge students work more effectively within the "developmentally appropriate" charity framework. Given the call for "democratic citizenship" and given what citizenship as I have presented herein involves, I am inclined to argue in favour of the former function. But regardless of what we believe the agenda of ISLPs should be, it is clear that these programs are not living up to whatever agenda they are currently setting for themselves through their appeals to "global citizenship" and the responsibility that entails.

I have thus far identified a central motivational conflict between self and other (and, further, between distributive/helping and cosmopolitan obligations) in international service learning projects. Engaging in development work for one's own benefit and growth takes communities of the Global South as means to an end in an unacceptably exploitative way. On the other hand, engaging in development work for the sake of helping others is a suspect claim to be treated with caution, due to its potential for breeding paternalistic/neocolonial interventions, or self-serving motivations 
masquerading as beneficence. ISLPs explicitly promote both self- and other-regarding motivations, sometimes simultaneously, often with reference to the goal of becoming a “global citizen." Yet testimonial evidence demonstrates a wide disparity in experience and outcomes of participation in ISLPs, especially with reference to one's orientation toward the world and emerging issues of global justice. Global citizenship is a concept at the core of many ISLPs and of development more generally, but it is a concept that remains ill-defined, inconsistently applied, and often ineffectual.

\subsection{Applying the Social Connection Model}

In this section, I will outline the contributions that the social connection model can make to ISLPs in its capacity as a tool for examining relationships, obligations, and responsibility. If ISLP participants take on the perspective imparted by the social connection model and use its components to structure their reflection, they will make greater gains in critical thinking about social justice responsibility and global relationality. The five components of the social connection model can help ISLP participants understand their relationship to and responsibility for structural injustice on a global scale, and guide collective action to combat the harms that stem from it. The social connection model will direct ISLP participants away from a helping mindset to the more sustained commitments and praxis of a cosmopolitan global citizen. In short, the incorporation of the social connection model will fulfill the hollow appeals of ISLPs to the concept of global citizenship.

Despite GVI's shaky reference to and use of the concept of global citizenship, their definition of international service learning is a solid reference point for the application of the social connection model. So, with that definition in mind, I state the 
three core components of an ISLP: participation in an organized service activity to address community needs; cross-cultural experience and dialogue; and active reflection on the experience, focused in part on global and intercultural issues. The key contribution of the social connection model will be to the third component of reflection, both in the form of pre-departure education and in the way participants are encouraged to actively and critically assess their experiences throughout the duration of the trip. Debriefing and reflection upon return are also an important part of the process in order for students to be able to contextualize their entire experience and integrate it with their lives and practice of citizenship at home. It is crucial that ISLP participants engage in substantial reflection on their experiences since "volunteer work in the developing world is often more about the search for self-identity, often through the amelioration of unanchored feelings of guilt, than it is about challenging the sources of the inequality that creates the conditions that enable individuals to perceive themselves as helping others" (Fizzell and Epprecht $2013,120)$. Challenging sources of inequality is the core of the project of cosmopolitan global citizenship and reflection guided by the components of the social connection model can help ISLP participants translate their misplaced feelings of guilt into a forward-looking praxis that dismantles inequality. In short, the transformative perspective-altering experience that ISLPs aim to provide takes place in that crucial reflection process, and will determine to what extent participants carry their cosmopolitan global citizenship into a true praxis over the course of their lives.

Once again, I turn to testimonial evidence to illustrate the need for a reflection process that helps channel participants' feelings into a project of activism rather than a project of emotional self-flagellation and penance. Recalling the last chapter's discussion 
of Arendt on guilt and responsibility, we recognize guilt as an inappropriate and counterproductive emotion for the circumstances. Yet guilt is often a prominent part of the ISLP experience either as a motivation for participating or in the wake of returning home. One student, recognizing the self-serving nature and outcomes of her international experiential learning trip, expressed that her memories of her time in Nairobi were "marked with the knowledge of people and resources I had used for the purposes of my own intellectual development - people I had promptly abandoned for the comforts of Canada when it was all said and done, people who provided me with opportunities" (Difruscio 2013, 125). She continues:

I feel overwhelming guilt for leaving people and unfinished projects. For choosing a certain amount of self-preservation over the work I was doing. For abandoning people, and coming out of it with a few more lines on my resume... And I feel disappointed in myself because I have yet to translate these experiences into something meaningful, let alone understand what it is for something to be meaningful. (Difruscio 2013, 126-127)

The student's identification of feelings of guilt, combined with the failure to integrate the work she did abroad with her life back in Canada, expresses a struggle to define and practice global citizenship when it is uncoupled from an international context and setting. This struggle is echoed in the experiences of yet another student, who recalls "Despite the profound impact that the dedication of these nurses had on me when I was in Peru, returning to Canada I could not help but feel disconnected from them and from my experiences in San Juan... I was struggling to hold on to the memories and the lessons I had learned abroad." (Matisz 2013, 129). I propose that a process of reflection guided by the social connection model could help these students and others like them build a concept of global citizenship that is congruent with but not dependent on international 
experience, and which shifts their focus away from guilt toward collaborative relationships of solidarity both within and across borders.

Recall that the five components of the social connection model are: non-isolation, judging background conditions, a forward-looking focus, emphasis on shared responsibility, and the prescription that this responsibility can only be discharged through collective action. I now aim to show how these five components, when used as guiding principles for ISLP activity, can mitigate counterproductive feelings of guilt, which are not conducive to a good praxis of cosmopolitan global citizenship. The guilt expressed by the first participant, stemming from her perception that she has abandoned people and projects in Nairobi, expresses a profound tension between the expectations perpetuated by the helping imperative and the reality of cosmopolitan obligations. As discussed above, the helping imperative disseminates the idea that engaging in service work abroad constitutes the terminal fulfilment of a distributive obligation and that this fulfilment is beneficial both to the host community and to the participant. However, upon confrontation of the complexity of cross-border relationships and obligations, this participant realizes she cannot simply pat herself on the back for a job well done. And absent a framework to work through her experience and the dissonance that resulted, she seems at a loss.

However, let us imagine how her experience could have been different if it had been informed by the values of the social connection model. The three most actively relational components of the social connection model—non-isolation, shared responsibility, and collective action—could have contributed to a more equitable and collaborative construction of the project itself and of the participant's perception and 
expectations thereof. The participant's reference to using people and resources "for the purposes of my own intellectual development" is reflective of an initially self-regarding approach to international experience — an approach about which the participant later feels profound discomfort. In contrast, the relational components of the social connection model allow for and encourage intellectual development, but emphasize that this development takes place not as a unilaterally reaped benefit but as an outcome of engagement in a community of global citizens aware of and acting on common obligations. To elaborate, the relational components foster an attitude of humility where the participant sees herself as collaborating in a pre-existing and ongoing project of global justice. This is at odds with, and an improvement on, the entitlement that ISLPs foster in their participants when projects are marketed as being primarily about the participants themselves. Feelings of guilt, by nature of their isolating and self-regarding focus, both come from and play into the notion that the ISLP experience is fundamentally about the participant and their individual role in global justice. This betrays a profound hubris, fostered in participants by ISLP marketing and by reification of Global North/Global South power asymmetry.

Non-isolation, however, encourages us to step away from this hubris, emphasizing that while we do individually bear responsibility for structural injustice it is not actually about us as individuals. Rather, it is about the way we as individuals are connected to others through the global systems in which we move: a holistic perspective that involves the individual but that does not revolve around her. Following from this, the component of shared responsibility alerts us to the fact that we are steeped in a community of citizens, with obligations incumbent upon us all. Lastly, the component of 
collective action further encourages the participant to see herself not as an individual working toward a terminal discharging of responsibility, but as one of many individuals engaging together in a praxis of global relationality—that is, cosmopolitan global citizenship. Being educated in and aware of the social connection model and its values pre-departure would thus set ISLP participants up to work more collaboratively and less exploitatively with their community partners in the Global South. Because of its broadened view of the role and importance of the individual, a social connection model perspective also has the benefit of lessening cognitive dissonance and feelings of guilt upon participants' return home, thereby facilitating momentum to continue the practice of global citizenship begun abroad.

The momentum of the praxis is intimately connected to another component of the social connection model—forward-looking focus. Recall from chapter 2 that guilt is identified with a backward-looking focus of fault-finding. As described above, ISLP participants may often engage in this backward-looking focus as they attempt to define their own role in structural injustice and in the intricacies of ISLPs themselves. But since the relational components of the social connection model discourage this kind of retrospective individualistic focus at both the systemic and personal level, ISLP participants with a social connection outlook will be much more likely to turn their attention to the future and to the constructive actions they can undertake. In other words, the cosmopolitan global citizen's response to backward-looking individualism is the forward-looking collaboration of the social connection model, which seeks not to assign blame to individuals but to take responsibility as a collective. Translating this responsibility into a praxis at home is not a simple task, but at the very least the social 
connection model's insistence on forward-looking focus highlights that it is a task we must meet head-on and with purpose. The second participant quoted in this section, who recalled struggling to hold onto the impact and lessons from her time abroad, offers an observation that affirms the conscious and intentional nature of fostering a forwardlooking focus:

Reflecting now on my experiences volunteering abroad, I have noticed a drastic change in my perspectives on the world... I now recognize that the process of putting these lessons into action is a work in progress that requires me to make a daily decision to be a more conscious and active citizen in my community. My visits to Peru were just the beginning of this process. (Matisz 2013, 130)

The participant's recognition of her ISLP experience as the beginning of a process indicates awareness and acceptance of cosmopolitan obligations that demand ongoing attention, and a commitment to active involvement in the making and remaking of her own practice of citizenship. Susan Murphy is quoted in the previous chapter as saying "acting to assist another may represent the beginning of a relationship rather than the complete fulfilment of a moral obligation" (Murphy 2014, 374). It seems that for this particular participant, the relationship is well under way.

The final contribution that the social connection model can make to ISLPs and to their promotion of good global citizenship is through the component of judging background conditions. Fizzell and Epprecht, quoted above, identify a core goal of volunteering abroad as "challenging the sources of the inequality that creates the conditions that enable individuals to perceive themselves as helping others". If ISLPs were structured with a pre-commitment to this holistic analysis focusing on the processes and institutions that determine distributive outcomes rather than on distributive outcomes exclusively, participants would have greater understanding of the root causes of global 
inequality and how they may play a role in those causes. In fact, the non-isolating, shared responsibility, and collective action components of the social connection model already encourage participants to consider these questions by asking them to see their individuality as inherently relational. Ultimately the five components of the social connection model are symbiotic, working together to encourage a broadened circle of concern wherein each one of us considers our vast relational impact both locally and globally.

\subsection{Conclusion}

My work in this thesis has been intended to show that global citizenship is a concept illdefined yet oft-cited in international service learning. One consequence of a poorly developed understanding of global citizenship is that the learning and worldview of ISLP participants suffers, making their involvement in ISLPs complicated at best and counterproductive at worst. These negative effects impair participants' ability to effectively conceptualize and practice global citizenship, thereby jeopardizing the larger project of global justice. I have argued for a humanized concept of cosmopolitanism, using the capabilities approach to connect the praxis of global citizenship to the beings and doings of people the world over. I have also appealed to Iris Marion Young's social connection model to situate my humanized cosmopolitan global citizenship in the realm of local and global relationality. Our relationships within and across borders imbue us with a variety of obligations, and it is the task of the cosmopolitan global citizen to attend to these obligations in an ongoing manner. I take my main contribution to be my identification of the social connection model as a framework for inquiry into the obligations and activities of a cosmopolitan global citizen, allowing people to discern 
what they ought to be doing in pursuit of global justice and in fulfillment of their obligations.

It is my hope that as an outgrowth of my work in this thesis, international service learning projects can be recognized and put to use as pedagogical tools in the education of cosmopolitan global citizens. This task is evidently under way already, given the appeals of ISLPs to the notion of global citizenship. However, it is imperative that the social connection model (or something like it) be included in this process as a way to mitigate harmful perceptions of what it means to "help", and skewed perspectives on how to best address structural injustice. Global citizenship is much more than a line on your resume, and the social connection model encourages people to move past this perception and to connect with the reality of their relationships and obligations. Strong grounding in the global relational landscape will shape people's sense of themselves and their role in the world, hopefully carrying them through a sustained and fulfilling praxis of global citizenship over the course of their lives. It is in this community of committed and engaged citizens that I rest my hope for a more just future: a future marked by common striving, solidarity, collaboration, and care. Perhaps such a vision of global community is too aspirational, but the merits of such a community warrant aspiration. And it is only when people dare to aspire to that global community that the "mental cosmopolis" we so desperately need will begin to take shape. 


\section{References}

AIESEC. 2016. “Social Internships.” Accessed March 16, 2017. http://aiesec.ca/socialinternships/.

"An Act to Encourage the Gradual Civilization of Indian Tribes in this Province, and to Amend the Laws Relating to Indians," 3rd Session, 5th Parliament, 1857.

Bellamy, Alex J., and Paul D. Williams. 2010. Understanding Peacekeeping. Cambridge: Polity Press.

Biccum, April. 2010. Global Citizenship and the Legacy of Empire: Marketing Development. New York: Routledge.

Brock, Gillian. 2013. "Contemporary Cosmopolitanism: Some Current Issues.” Philosophy Compass 8: 689-698.

Cameron, John D. 2013. "Grounding Experiential Learning in 'Thick' Conceptions of Global Citizenship." In Globetrotting or Global Citizenship? Perils and Potentials of Experiential Learning, edited by Rebecca Tiessen and Robert Huish, 21-42. Toronto: University of Toronto Press.

Clark, Jenny. 2017. "What Is International Service Learning?” Accessed March 16, 2017. http://www.gviusa.com/blog/what-is-international-service-learning/.

Coulthard, Glen. 2008. "Beyond Recognition: Indigenous Self-Determination as Prefigurative Practice." In Lighting the Eighth Fire: The Liberation, Resurgence, and Protection of Indigenous Nations, edited by Leanne Simpson, 187-201. Winnipeg: Arbeiter Ring Publishing.

Crey, Karrmen. 2009. "Enfranchisement.” Accessed March 10, 2017. http://indigenousfoundations.arts.ubc.ca/enfranchisement/.

Difruscio, Cathleen. 2013. "All in.” In The World Is My Classroom: International Learning and Canadian Higher Education, edited by Joanne Benham Rennick and Michel Desjardins, 124-127. Toronto: University of Toronto Press.

Difruscio, Cathleen, and Joanne Benham Rennick. 2013. "Culture Shock, Cognitive Dissonance, or Cognitive Negotiation? Terms Matter in International Service Learning Programs." In The World Is My Classroom: International Learning and Canadian Higher Education, edited by Joanne Benham Rennick and Michel Desjardins, 63-84. Toronto: University of Toronto Press.

Dower, Nigel. 2002. “Global Citizenship: Yes or No?” In Global Citizenship: A Critical Introduction, edited by Nigel Dower and John Williams. New York: Routledge.

Dower, Nigel, and John Williams. 2002. Global Citizenship: A Critical Introduction. New York: Routledge.

Explorica. n.d. "Make a Difference: Impactful Service Learning Tours.” Accessed March 16, 2017. http://www.explorica.ca/servicetrips. 
Fizzell, Kathryn, and Marc Epprecht. 2013. "Experiential Learning in Challenging Settings: Lessons from Post-Genocide Rwanda." In Globetrotting or Global Citizenship? Perils and Potential of International Experiential Learning, edited by Rebecca Tiessen and Robert Huish, 112-139. Toronto: University of Toronto Press.

Global Citizen Travel. 2012. "Our Mission.” Accessed March 16, 2017. http://www.globalcitizenstravel.com/about?p=mission.

GVI World. 2012. “About Us.” Accessed March 16, 2017. http://www.gviworld.com/about-us/.

Held, David. 2010. Cosmopolitanism: Ideals and Realities. Cambridge: Polity Press.

Heron, Barbara. 2007. Desire for Development: Whiteness, Gender, and the Helping Imperative. Waterloo, ON: Wilfrid Laurier University Press.

Holden Center. 2017. “Alternative Breaks.” Accessed March 16, 2017. https://holden.uoregon.edu/alternative-breaks.

Kielburger, Craig, and Mark Kielburger. 2013. Foreword to The World Is My Classroom: International Learning and Canadian Higher Education, edited by Joanne Benham Rennick and Michel Desjardins, xi-xvi. Toronto: University of Toronto Press.

Marciniak, Katarzyna. 2013. "Legal/illegal: protesting citizenship in Fortress America." Citizenship Studies 17(2): 260-277.

Matisz, Lynn. 2013. "Staying involved." In The World Is My Classroom: International Learning and Canadian Higher Education, edited by Joanne Benham Rennick and Michel Desjardins, 127-130. Toronto: University of Toronto Press.

Matthews, Sara. 2013. "Rethinking the 'Good' in Good Global Citizenship: The Ethics of Cosmopolitan Pluralism." In The World Is My Classroom: International Learning and Canadian Higher Education, edited by Joanne Benham Rennick and Michel Desjardins, xi-xvi. Toronto: University of Toronto Press.

Mayhew, Matthew J., and Mark E. Engberg. 2011. "Promoting the Development of Civic Responsibility: Infusing Service-Learning Practices in First-Year 'Success' Courses." Journal of College Student Development 52(1): 20-38.

McCardle, Bennett. 2014. "Enfranchisement." The Canadian Encyclopedia. http://www.thecanadianencyclopedia.ca/en/article/enfranchisement/.

Murphy, Susan. 2014. "Unlocking the beauty of the imperfect duty to aid: Sen's idea of the duty of assistance." Journal of Global Ethics 10(3): 369-383.

Nussbaum, Martha C. 1994. "Patriotism and Cosmopolitanism." Boston Review 19(5). http://bostonreview.net/martha-nussbaum-patriotism-and-cosmopolitanism.

Nussbaum, Martha C. 2011. Creating Capabilities: The Human Development Approach. Cambridge, MA: Belknap Press. 
Nussbaum, Martha C. 2016. Anger and Forgiveness: Resentment, Generosity, Justice. Oxford: Oxford University Press.

Rennick, Joanne Benham, and Michel Desjardins. 2013. The World Is My Classroom: International Learning and Canadian Higher Education. Toronto: University of Toronto Press.

Sen, Amartya. 1999. Development as Freedom. Oxford: Oxford University Press.

The South Commission. The Challenge to the South: The Report of the South Commission. Oxford: Oxford University Press, 1990.

Tiessen, Rebecca. 2013. "Career Aspirations and Experiential Learning Abroad: Perspectives from Canadian Youth on Short-Term Placements." In Globetrotting or Global Citizenship? Perils and Potentials of Experiential Learning, edited by Rebecca Tiessen and Robert Huish, 21-42. Toronto: University of Toronto Press.

Tiessen, Rebecca, and Robert Huish. 2013. "International Experiential Learning and Global Citizenship.” In Globetrotting or Global Citizenship? Perils and Potentials of Experiential Learning, edited by Rebecca Tiessen and Robert Huish, 21-42. Toronto: University of Toronto Press.

Truth and Reconciliation Canada. 2015. Honouring the Truth, Reconciling for the Future: Summary of the Final Report of the Truth and Reconciliation Commission of Canada. Winnipeg: Truth and Reconciliation Commission of Canada.

Tully, James. 2014. On Global Citizenship: James Tully In Dialogue. New York: Bloomsbury.

Tully, James. 2005. “Two Meanings of Global Citizenship: Modern and Diverse.” Paper presented to The Meanings of Global Citizenship Conference, Liu Centre and Trudeau Foundation, University of British Columbia, September 9-10.

Western University. 2014. "Achieving Excellence on the World Stage.” Accessed August 15, 2016. http://president.uwo.ca/pdf/strategicplan/WesternU_Full_StratPlan_2014.pdf (accessed August 15, 2016).

Western University. 2016. “Alternative Spring Break.” Accessed August 15, 2016. http://asb.uwo.ca/.

Xperitas. 2017. “About Us.” Accessed March 16, 2017. http://www.xperitas.org/aboutus.

Young, Iris Marion. 1990. Justice and the Politics of Difference. Princeton: Princeton University Press.

Young, Iris Marion. 2011. Responsibility for Justice. New York: Oxford University Press. 